\title{
INTEL 8085 Implementation of Byte-Wise Data Encryption using Successive RSA Algorithm coupled with Random Initial Primes
}

Ashish Menon

Indian Institute of Technology Guwahati

ashish18@iitg.ac.in

June 15, 2020

Abstract

This paper, discusses the implementation of RSA (Rivest-Shamir-Adleman) algorithm of encrypting and decrypting data. This is an assymetric algorithmic approach, which implies that two different keys, one public and another private have been used to accomplish the purpose. This paper also extends the application of RSA algorithm by choosing random prime numbers for every byte of transferred data. The programs involved are entirely based on the microprocessor INTEL 8085.

\section{Contents}

2 RSA Algorithm 2

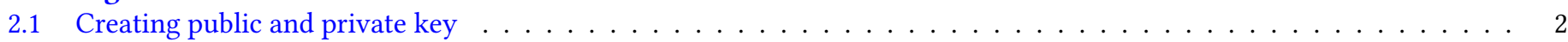

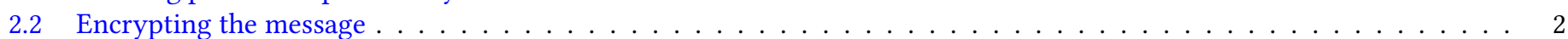

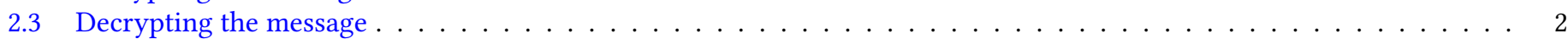

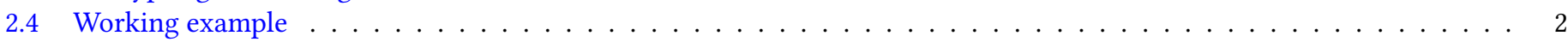

3 Implementation with 8085

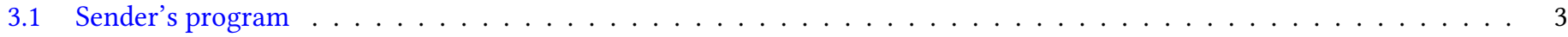

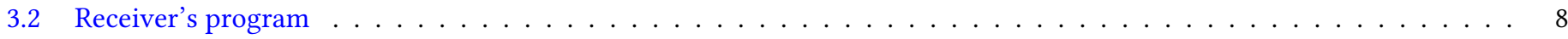

4 Utilizing random primes for encrypting long data byte-wise 12

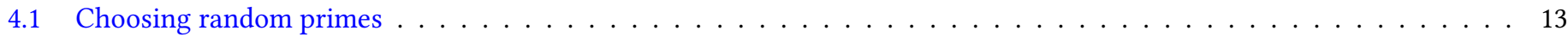

4.28085 program for generating random numbers between $0-12$ (inclusive) . . . . . . . . . . . . . . . . . . . 14

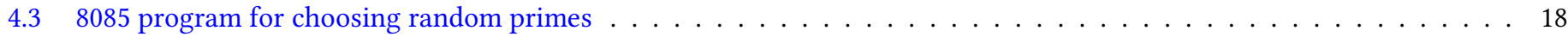

5 Choose value of public and private key exponent for random primes 19

6 Final implementation of encryption for transferring $1 \mathrm{kB}$ of data 21

7 Conclusion 30

References 30 


\section{Introduction}

RSA (Rivest-Shamir-Adleman) is a public key encryption technique and is considered one of the most secure encryption techniques used by modern computers. This is an asymmetric algorithm, which means that two separate keys are involved. One of them is called the public key and is visible to everyone. The one is a private key and should not be shared with anyone other than the receiver. The algorithm is centered around the fact that finding the factors of a sufficiently large composite number is impossible in practice when the factors are prime numbers. The algorithm of this technique is discussed in the following section. Later, we deal with implementation of choosing random set of prime numbers for encrypting every byte of data by the Linear Congruential Generator (LCG) algorithm. To modularize the work done in this paper, we will take a bottom-up approach. First, we will deal with implementing a classic RSA algorithm to encrypt (at the sender's end) one byte of data and decrypt it (at the receover's end) upon successful receipt. After this is done, we will discuss how the random choice of a set of initial prime numbers (which is the trademark of the RSA algorithm) is implemented.

\section{RSA Algorithm}

The classic RSA algorithm involves three steps: Creating public and private keys, encrypting message at sender's end and decrypting message at receiver's end. Each of these is discussed below:

\subsection{Creating public and private key}

- Step 1. Choose two large random prime numbers $p$ and $q$.

- Step 2. Compute the product of the two primes $n=p . q \longrightarrow$ (eq. 2.01).

- Step 3. Compute totient $\phi(n)=(p-1)(q-1) \longrightarrow$ (eq. 2.02).

- Step 4. Select an integer $e$ such that $1 \leq e \leq \phi(n)$ and $\operatorname{gcd}(e, \phi(n))=1$ where $\operatorname{gcd}($.$) refers to the greatest common divisor.$

- Step 5. Compute $d$, such that the following congruence relation is satisfied: $d e \equiv 1(\bmod \phi(n)) \longrightarrow$ (eq. 2.03).

The public key is the set $P=\{e, n\}$ and the private key is the set $P^{\prime}=\{d, p, q\}$. The strength of the encryption increases exponentially with the increasing number of key bits. Typically 1024 or 2048 bits long key size are used.

\subsection{Encrypting the message}

Usually while implementation, the RSA must be combined with some sort of padding scheme so that no message results in insecure cipher texts. In this project however, we will not discuss this bit. It is assumed that all the input information that is to be sent to the receiver is already processed by the agreed-upon reversible protocol. Say the sender wants to send a message $m$ to the receiver. Due to padding, $m \leq n$. First the receiver should share his/her public key $P=\{e, n\}$ with the sender. The sender will then compute the corresponding cipher text by:

$$
c=m^{e} \bmod n \longrightarrow(\text { eq.2.04) }
$$

Then the sender will send the cipher text $c$ to the receiver.

\subsection{Decrypting the message}

To decrypt the cipher text, the receiver has to make use of his/her private key as follows:

$$
m=c^{d} \bmod p q \longrightarrow \text { (eq.2.05) }
$$

Ans thus the original message $m$ is recovered back from the cipher text.

\subsection{Working example}

In this paper, we will see the encryption and decryption pertaining to one byte of data. Let us choose the prime numbers as $p=67$ and $q=83$. Then from eq. 2.01 and 2.02 we have, $n=5561$ and $\phi(n)=5412$. We choose $e=17$ because $\operatorname{gcd}(17,5412)=1$. From eq. 2.03, we set $d=9869$.

Say the sender wants to transfer the number $m=103$ to the receiver. From eq. 2.04, we have $c=103^{17} \bmod 5561=1413$. Similarly, in the receiver's end, from eq. 2.05 we have, $m=1413^{9869} \bmod 5561=103$. We will implement this transmission using 8085 in the following sections.

Note that the values of the key components are unique to this simulation. But, the message $m$ is not. $m=103$ was just a random choice that was made. We want to build a program which can transfer any data that is one byte long. So, in eq. 2.04, 
$\max \left(m^{e}\right)=256^{17}$ which would be 17 bytes long. Also $\max (c)=5560$ In eq. 2.05 , $\max \left(c^{d}\right)=5560^{9869}$. Taking the logarithm of this value to the base of 256 we get 15347.367 , which means that the maximum value is atleast 15348 bytes long.

\section{Implementation with 8085}

Now, in practice the prime numbers that are used in the RSA algorithm are 1024 or 2048 bits (128 or 256 bytes) long. But for simplicity, we've constrained ourselves to 1 byte long primes $(p=67$ and $q=83)$. In this section, the working example discussed in section 2.4 is programmed. Two separate programs have to be written each for the sender's and receiver's end. In writing each of these programs, much energy is spent in calculating the exponents and modulo given in eq. 2.04 and 2.05, primarily because of the large number of bytes. The algorithms for the same and the program codes are discussed in the following sections.

\subsection{Sender's program}

As discussed in section 2.4, in the sender's end a maximum of 17 bytes would be involved in the calculations of eq. 2.04. We require atleast 17 bytes of data to store $m^{e}$. We will utilize the addresses FFEF to FFFF to store the bytes of the same in decreasing order of significance i.e. MSB (most significant byte) will be stored in address FFEF and LSB (least significant byte) will be store in address FFFF. The calculation of $m^{e}$ is done on the following understanding:

$$
\begin{aligned}
m^{e} & =\underbrace{m \cdot m^{e-1}}_{m \text { times }} \underbrace{m^{e-1}+m^{e-1}+\cdots+m^{e-1}}_{m \text { times }} \\
& =\underbrace{(\underbrace{m^{e-2}+\cdots+m^{e-2}}_{m \text { times }})+\cdots+\underbrace{\left(m^{e-2}+\cdots+m^{e-2}\right.}_{m \text { times }})}_{m \text { times }} \\
& \vdots \underbrace{(\cdots(\underbrace{m+m+\cdots+m}_{\text {times }})+(\underbrace{m+m+\cdots+m}_{m \text { times }})+\cdots+(\underbrace{m+\cdots}_{m+m+\cdots+m})+\cdots)}_{m \text { times }}
\end{aligned}
$$

The flowcharts for calculating $m^{e}$ and modulo $n$ of the same are given below. 


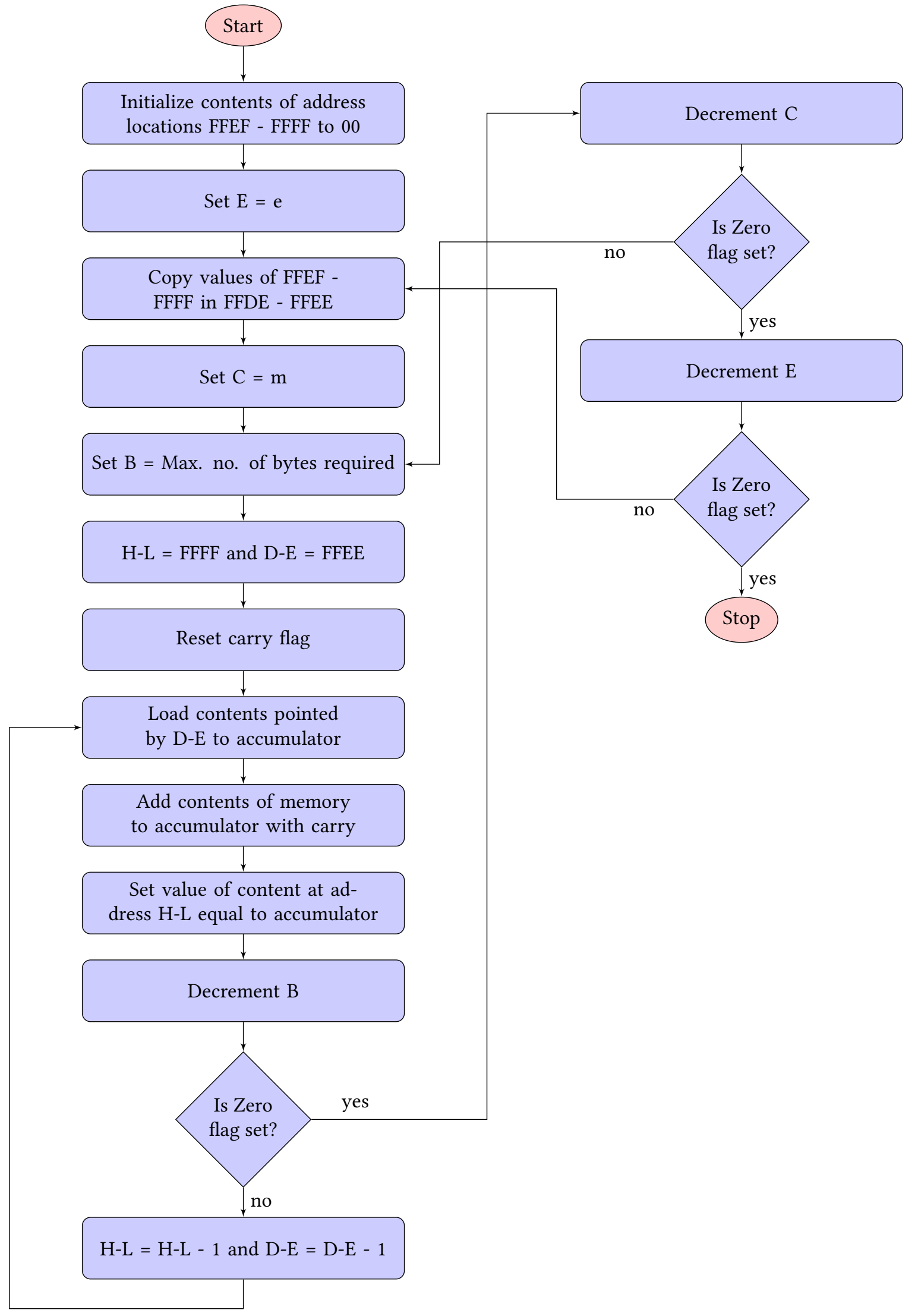

Figure 1: Flowchart for calculation of $\mathrm{m}^{\mathrm{e}}$ 

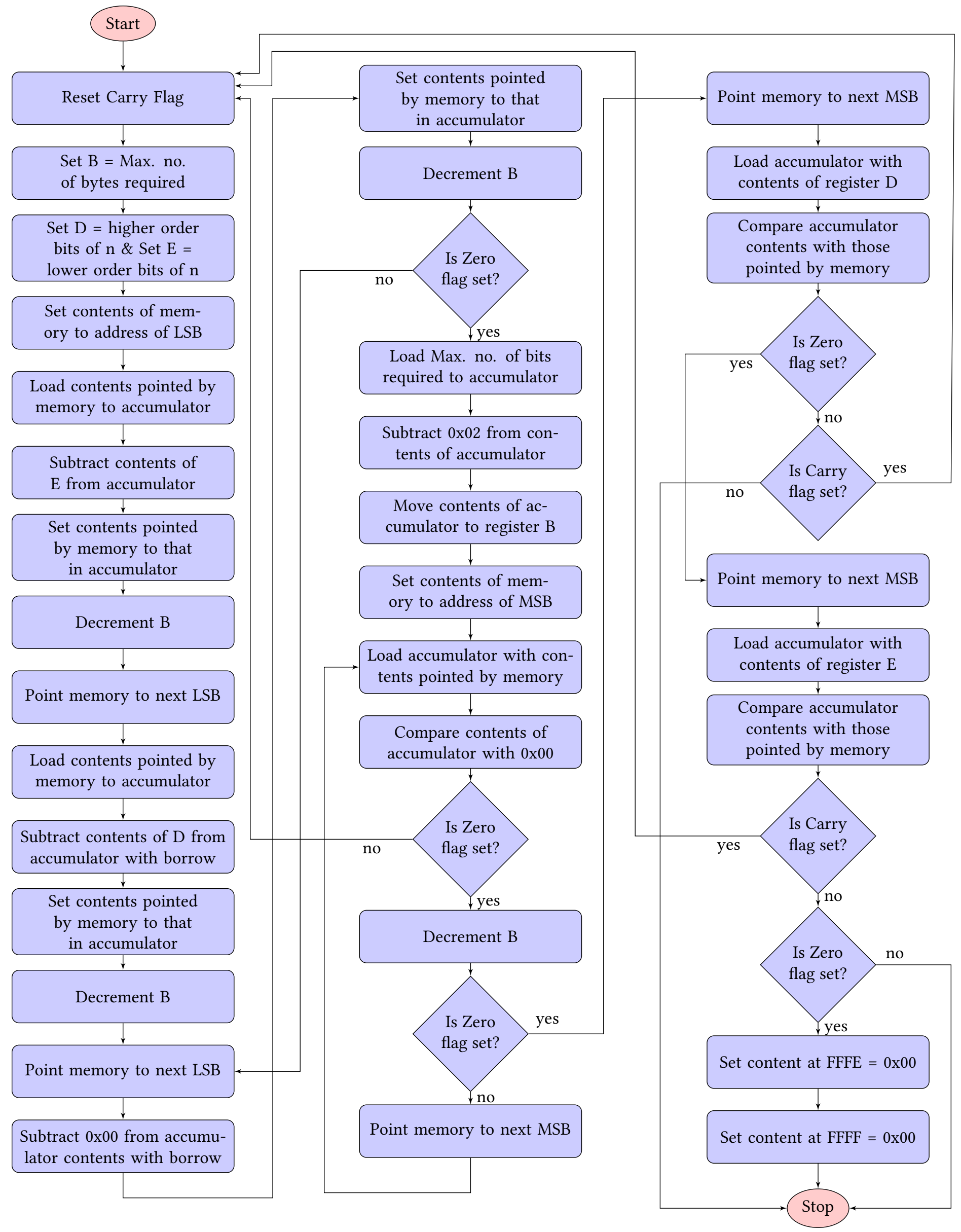

Figure 2: Flowchart for calculation of $\mathrm{m}^{\mathrm{e}} \bmod \mathrm{n}$ 


\begin{tabular}{|c|c|}
\hline $\mathrm{C} 000$ & \\
\hline $\mathrm{C} 002$ & \\
\hline $\mathrm{C} 005$ & \\
\hline $\mathrm{C} 007$ & \\
\hline $\mathrm{C} 00 \mathrm{~A}$ & \\
\hline $\mathrm{C} 00 \mathrm{C}$ & \\
\hline $\mathrm{C} 00 \mathrm{~F}$ & \\
\hline $\mathrm{C} 011$ & \\
\hline $\mathrm{C} 014$ & \\
\hline $\mathrm{C} 016$ & \\
\hline C019 & \\
\hline $\mathrm{C} 01 \mathrm{C}$ & \\
\hline C01D & \\
\hline $\mathrm{C} 020$ & LOOP1 \\
\hline $\mathrm{C} 022$ & \\
\hline $\mathrm{C} 023$ & \\
\hline $\mathrm{C} 024$ & \\
\hline $\mathrm{C} 027$ & \\
\hline $\mathrm{C} 028$ & \\
\hline $\mathrm{C} 02 \mathrm{~B}$ & LOOP2 \\
\hline $\mathrm{C} 02 \mathrm{C}$ & \\
\hline C02D & \\
\hline $\mathrm{C} 030$ & \\
\hline $\mathrm{C} 031$ & \\
\hline $\mathrm{C} 034$ & \\
\hline C035 & REPEAT1 \\
\hline C038 & \\
\hline C03B & REPEAT \\
\hline $\mathrm{C} 03 \mathrm{C}$ & \\
\hline C03D & \\
\hline C03E & \\
\hline $\mathrm{C} 041$ & \\
\hline $\mathrm{C} 042$ & \\
\hline $\mathrm{C} 043$ & \\
\hline $\mathrm{C} 046$ & DONE \\
\hline $\mathrm{C} 049$ & \\
\hline $\mathrm{C} 04 \mathrm{~A}$ & LOOP4 \\
\hline C04D & \\
\hline $\mathrm{C} 04 \mathrm{E}$ & \\
\hline $\mathrm{C} 051$ & \\
\hline $\mathrm{C} 054$ & \\
\hline $\mathrm{C} 055$ & \\
\hline C056 & LOOP5 \\
\hline $\mathrm{C} 057$ & \\
\hline $\mathrm{C} 058$ & \\
\hline $\mathrm{C} 059$ & \\
\hline $\mathrm{C} 05 \mathrm{~A}$ & \\
\hline C05D & \\
\hline $\mathrm{C} 05 \mathrm{E}$ & \\
\hline $\mathrm{C} 05 \mathrm{~F}$ & \\
\hline $\mathrm{C} 062$ & NEXT \\
\hline $\mathrm{C} 063$ & \\
\hline $\mathrm{C} 066$ & \\
\hline $\mathrm{C} 069$ & LOOP3 \\
\hline $\mathrm{C} 06 \mathrm{~A}$ & \\
\hline
\end{tabular}

MNEMONICS
MVI A, $67(\mathrm{H})$
STA C407(H)
MVI A, $11(\mathrm{H})$
STA C $408(\mathrm{H})$
MVI A, $11(\mathrm{H})$
STA C409(H)
MVI A, $15(\mathrm{H})$
STA C40A $(\mathrm{H})$
MVI A, B9 $(\mathrm{H})$
STA C40B $(\mathrm{H})$
LDA C408 $(\mathrm{H})$
MOV E, A
LXI H, FFEF $(\mathrm{H})$
MVI A, $00(\mathrm{H})$
MOV M, A
DCR E
JZ LOOP2

HEX CODES

$3 \mathrm{E}, 67$

$32,07, \mathrm{C} 4$

$3 \mathrm{E}, 11$

$32,08, \mathrm{C} 4$

$3 \mathrm{E}, 11$

$32,09, \mathrm{C} 4$

$3 \mathrm{E}, 15$

$32,0 \mathrm{~A}, \mathrm{C} 4$

$3 \mathrm{E}, \mathrm{B} 9$

$32,0 \mathrm{~B}, \mathrm{C} 4$

$3 \mathrm{~A}, 08, \mathrm{C} 4$

$5 \mathrm{~F}$

$21, \mathrm{EF}, \mathrm{FF}$

$3 \mathrm{E}, 00$

77

1D

CA, 2 B , C0

INX H

JMP LOOP1

23

C3, $20, \mathrm{C} 0$

STC 37

CMC $3 \mathrm{~F}$

LDA C408(H) 3A, $08, \mathrm{C} 4$

MOV E, A $5 \mathrm{~F}$

LDA C409(H) 3A, $09, \mathrm{C} 4$

MOV B, A 47

LXI H FFDE $(\mathrm{H}) \quad 21, \mathrm{DE}, \mathrm{FF}$

LXI D FFEF $(\mathrm{H}) \quad 11, \mathrm{EF}, \mathrm{FF}$

LDAX D $1 \mathrm{~A}$

MOV M, A $\quad 77$

DCR B 05

JZ DONE CA, $46, \mathrm{C} 0$

INX H 23

INX D 13

JMP REPEAT C3, 3 B, C0

LDA $\mathrm{C} 407(\mathrm{H}) \quad 3 \mathrm{~A}, 07, \mathrm{C} 4$

MOV C, A $4 \mathrm{~F}$

LDA $\mathrm{C} 409(\mathrm{H}) \quad 3 \mathrm{~A}, 09, \mathrm{C} 4$

MOV B, A 47

LXI H FFFF (H) 21, FF, FF

LXI D FFEE $(\mathrm{H}) \quad 11, \mathrm{EE}, \mathrm{FF}$

STC

CMC

LDAX D

ADC $M$

MOV M, A

DCR B

JZ NEXT

DCX H

DCX D

JMP LOOP5

DCR C

JZ LOOP3

JMP LOOP4

DCR E

JZ LOOP8
37

$3 \mathrm{~F}$

$1 \mathrm{~A}$

$8 \mathrm{E}$

77

05

$\mathrm{CA}, 62, \mathrm{C} 0$

$2 \mathrm{~B}$

$1 \mathrm{~B}$

$\mathrm{C} 3,56, \mathrm{C} 0$

$0 \mathrm{D}$

$\mathrm{CA}, 69, \mathrm{C} 0$

C3 , 4 A, C0

$1 \mathrm{D}$

$\mathrm{CA}, 70, \mathrm{C} 0$
COMMENTS

Store $\mathrm{m}=103=0 \times 67$

Store $\mathrm{e}=17=0 \times 11$

Store max byte size $=17=0 \times 11$

$\mathrm{n}=5561=0 \times 15 \mathrm{~B} 9$

Store higher order bit of $\mathrm{n}=0 \times 15$

Store lower order bit of $\mathrm{n}=0 \times \mathrm{xB} 9$

Move e to reg. E

Initialize reg. pair HL with address of MSB

Initialize data at memory location to $0 \times 00$

If all 17 address locations are initialized to $0 \times 00$, go to LOOP2

If all 17 address location are not initialized point memory next address byte \& go to LOOP1

Reset Carry flag

Load e to reg. E

Store max byte size in reg. B

H-L points to content at address FFDE

D-E points to MSB which will converge to c

Copy content of DE reg, pair to memory

Check if all 17 bytes are copied

If yes, go to DONE

Else, increment contents of HL reg. pair

And increment contents of DE reg. pair

An then go to REPEAT

Store $m$ in $r e g . C$

Store max byte size in reg. B

Memory points to actual LSB

DE reg. pair points to copy LSB

Reset carry flag

Add copy LSB to actual LSB

Indicates that current byte is updated

If all bytes are updated go to NEXT

Else, point memory to next LSB

Point DE reg. pair to next LSB of copy

And go to LOOP5

Indicates that current iteration is done

If all $\mathrm{m}$ iterations are done, go to LOOP3

If not, go to LOOP4

Indicates that current iteration is done

If all e iterations are completed go to LOOP8 
LABEL

C06D

$\mathrm{C} 070$

$\mathrm{C} 071$

$\mathrm{C} 072$

$\mathrm{C} 075$

C076

C079

C07A

C07D

C07E

C081

C082

$\mathrm{C} 083$

C084

C085

$\mathrm{C} 086$

C087

$\mathrm{C} 088$

C089

$\mathrm{C} 08 \mathrm{~A}$

$\mathrm{C} 08 \mathrm{~B}$

$\mathrm{C} 08 \mathrm{C}$

C08E

$\mathrm{C} 08 \mathrm{~F}$

C090

C093

C096

C099

$\mathrm{C} 09 \mathrm{~B}$

$\mathrm{C} 09 \mathrm{C}$

$\mathrm{C} 09 \mathrm{~F}$

C100

C102

C105

C106

C109

C10A

C10D

C10E

C10F

C110

C113

C116

C119

C11A

C11B

LOOP8

LOOP7

LOOP9

LOOP9

.

(2)
MNEMONICS

JMP REPEAT1

STC

CMC

LDA C409(H)

MOV B, A

LDA $\mathrm{C} 40 \mathrm{~A}(\mathrm{H})$

MOV D, A

LDA C40B (H)

MOV E, A

LXI H, FFFF $(\mathrm{H})$

MOV A,M

SUB $E$

MOV M, A

DCR B

DCX H

MOV A,M

SBB D

MOV M, A

DCR B

DCX $\mathrm{H}$

MOV A,M

SBI $00(\mathrm{H})$

MOV M, A

DCR B

JZ LOOP7

JMP LOOP6

LOOP10

OOP11

JC LOOP8

JMP LOOP12

INX $\mathrm{H}$

MOV A, E

CMP M
HEX CODES

$\mathrm{C} 3,35, \mathrm{C} 0$

37

$3 \mathrm{~F}$

$3 \mathrm{~A}, 09, \mathrm{C} 4$

47

$3 \mathrm{~A}, 0 \mathrm{~A}, \mathrm{C} 4$

57

$3 \mathrm{~A}, 0 \mathrm{~B}, \mathrm{C} 4$

$5 \mathrm{~F}$

$21, \mathrm{FF}, \mathrm{FF}$

$7 \mathrm{E}$

93

77

05

2B

$7 \mathrm{E}$

$9 \mathrm{~A}$

77

05

2B

$7 \mathrm{E}$

DF , 00

77

05

CA, $96, \mathrm{C} 0$

$\mathrm{C} 3,8 \mathrm{~A}, \mathrm{C} 0$

$3 \mathrm{~A}, 09, \mathrm{C} 4$

D6, 02

47

$21, \mathrm{EF}, \mathrm{FF}$

$7 \mathrm{E}$

FE , 00

$\mathrm{C} 2,70, \mathrm{C} 0$

05

CA, 0D, C1

23

C 3,9 F , C0

23

$7 \mathrm{~A}$

BE

CA, $19, \mathrm{C} 1$

DA, 70 , C0

C3, 2 C, C1

23

$7 \mathrm{~B}$

$\mathrm{BE}$
COMMENTS

Else, go to REPEAT1

Reset Carry flag

Load max byte no. to reg. B

Load higher order bit of $n$ to reg. D

Load lower order bit of $n$ to reg. E

Initialize reg. pair HL with address of LSB

Subtract lower order bit of $\mathrm{n}$ from LSB

Update value of LSB

Indicates that LSB is updated

Point memory to next LSB

Subtract higher order bit of $\mathrm{n}$ from second LSB with borrow

Update value of second LSB

Indicates that second LSB is updated

Point memory to next LSB

Subtract $0 \times 00$ from current byte with borrow Update value of current byte

Indicates that current byte has been updated

If all bytes of current iteration are updated go to LOOP7

If all bytes of current iteration are not updated, go to LOOP6

Subtract $0 \times 02$ from max bit size

Store max bit size -2 in reg. B

Load memory with address of MSB

Compare current byte with $0 \times 00$

If current byte is not $0 \times 00$, go to LOOP8

Indicates that current byte has been found to be $0 \times 00$

If first 15 bytes have been compared go to LOOP10

If first 15 bytes have not yet been compared point memory to next MSB

Compare higher order bits of $n$ with data at address FFFE

If they are equal, go to LOOP 11

If they are not equal and address at FFFE is greater than higher order bits of $n$, go to LOOP8

Else if they are equal and address at FFFE is less than higher order bits of $n$, terminate the program.

Compare lower order bits of $\mathrm{n}$ with data at address FFFF 


\begin{tabular}{|c|c|c|c|c|}
\hline & LABEL & MNEMONICS & HEX CODES & COMMENTS \\
\hline $\mathrm{C} 11 \mathrm{C}$ & & JC LOOP8 & $\mathrm{DA}, 70, \mathrm{C} 0$ & $\begin{array}{l}\text { If address at FFFF is less than the lower } \\
\text { order bits of } n \text {, go to LOOP8 }\end{array}$ \\
\hline $\mathrm{C} 11 \mathrm{~F}$ & & JNZ LOOP12 & $\mathrm{C} 2,2 \mathrm{C}, \mathrm{C} 1$ & $\begin{array}{l}\text { Else if they are not equal, terminate the } \\
\text { program }\end{array}$ \\
\hline $\mathrm{C} 122$ & & MVI A, $00(\mathrm{H})$ & $3 \mathrm{E}, 00$ & Else if they are equal, proceed \\
\hline C 124 & & STA $\operatorname{FFFE}(\mathrm{H})$ & $32, \mathrm{FE}, \mathrm{FF}$ & Set value at address FFFE $=0 \times 00$ \\
\hline $\mathrm{C} 127$ & & MVI A, $00(\mathrm{H})$ & $3 \mathrm{E}, 00$ & \\
\hline C 129 & & STA $\operatorname{FFFF}(\mathrm{H})$ & $32, \mathrm{FF}, \mathrm{FF}$ & Set value at address FFFF $=0 \times 00$ \\
\hline $\mathrm{C} 12 \mathrm{C}$ & LOOP12 & HLT & 76 & \\
\hline
\end{tabular}

Note that since the $n=5561$, maximum value of $c$ from eq. 2.04 is 5560 which is a 2 byte data. Hence, after running the code above, the MSB and LSB of the cipher text will be stored in addresses FFEF and FFFF respectively. Now, these bytes will be transferred from the sender to the receiver. In this paper, this transmission is not discussed. However, we will implement the program to decrypt the cipher test at the receiver's end in the section 3.2 .

\subsection{Receiver's program}

The algorithm used to decrypt the cipher text is exacty the same as that used to encrypt the message, the only difference being the constants over which the algorithm is performed. By comparing eq. 2.04 and 2.05, it becomes evident that substituting $\mathbf{c}$ in place of $\mathbf{m}$ and $\mathbf{d}$ in place of $\mathbf{e}$, the code in section 3.1 can be easily modified to suit the receiver. In addition to this, it is also necessary to explicitly calculate $n=p$.q. This is because $n$ is not provided in the private key $P^{\prime}$. As section in section 2.4 , atleast $15348=0 \mathrm{x} 3 \mathrm{BF} 4$ bytes would be required for the arithmetic involved in eq. 2.05. We use the addresses C40C - C40B to store the byte values. We use also assume that the 2 bytes of the cipher text $c=1413=0 \times 0585$ (from section 2.4) that was sent from the sender is stored in the microprocessor of the receiver in addresses C404 (MSB) and C405 (LSB). The program is implemented below.

\section{LABEL}

$\mathrm{C} 000$

$\mathrm{C} 002$

$\mathrm{C} 005$

$\mathrm{C} 007$

C00A

C00C

$\mathrm{C} 00 \mathrm{~F}$

$\mathrm{C} 011$

$\mathrm{C} 014$

$\mathrm{C} 016$

$\mathrm{C} 019$

C01B

C01E

C020

C023

C025

C028

$\mathrm{C} 02 \mathrm{~B}$

$\mathrm{C} 02 \mathrm{C}$

C02E

C031

$\mathrm{C} 034$

C035

$\mathrm{C} 036$

C037

C03A

C03B

C03E

\begin{tabular}{|c|c|}
\hline MNE & MONICS \\
\hline MVI & $\mathrm{A}, 05(\mathrm{H})$ \\
\hline STA & $\mathrm{C} 404(\mathrm{H})$ \\
\hline MVI & $\mathrm{A}, 85(\mathrm{H})$ \\
\hline STA & $\mathrm{C} 405(\mathrm{H})$ \\
\hline MVI & $\mathrm{A}, 26(\mathrm{H})$ \\
\hline STA & $\mathrm{C} 406(\mathrm{H})$ \\
\hline MVI & $\mathrm{A}, 8 \mathrm{D}(\mathrm{H})$ \\
\hline STA & $\mathrm{C} 407(\mathrm{H})$ \\
\hline MVI & $\mathrm{A}, 3 \mathrm{~B}(\mathrm{H})$ \\
\hline STA & $\mathrm{C} 408(\mathrm{H})$ \\
\hline MVI & $\mathrm{A}, \mathrm{F} 4(\mathrm{H})$ \\
\hline STA & $\mathrm{C} 409(\mathrm{H})$ \\
\hline MVI & $\mathrm{A}, 43(\mathrm{H})$ \\
\hline STA & $\mathrm{C} 40 \mathrm{~A}(\mathrm{H})$ \\
\hline MVI & $\mathrm{A}, 53(\mathrm{H})$ \\
\hline STA & $\mathrm{C} 40 \mathrm{~B}(\mathrm{H})$ \\
\hline LDA & $\mathrm{C} 40 \mathrm{~A}(\mathrm{H})$ \\
\hline MOV & $\mathrm{E}, \mathrm{A}$ \\
\hline MVI & $\mathrm{D}, 00(\mathrm{H})$ \\
\hline LXI & $\mathrm{H}, 0000(\mathrm{H})$ \\
\hline LDA & $\mathrm{C} 40 \mathrm{~B}(\mathrm{H})$ \\
\hline MOV & $\mathrm{B}, \mathrm{A}$ \\
\hline $\mathrm{DAD}$ & $\mathrm{D}$ \\
\hline DCR & B \\
\hline JNZ & LOOP12 \\
\hline MOV & $\mathrm{A}, \mathrm{H}$ \\
\hline STA & $\mathrm{C} 402(\mathrm{H})$ \\
\hline MOV & $\mathrm{A}, \mathrm{L}$ \\
\hline
\end{tabular}

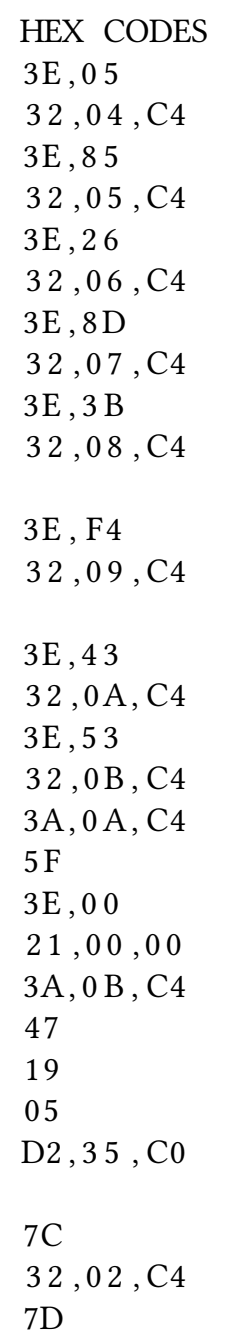

\section{COMMENTS}

Store higher order bits of $\mathrm{c}=0 \times 05$

Store lower order bits of $\mathrm{c}=0 \times 85$

Store higher order bits of $d=0 \times 26$

Store lower order bits of $\mathrm{d}=0 \times 8 \mathrm{D}$

Store higher order bits of max. byte size required $=0 \times 3 \mathrm{~B}$

Store lower order bits of max. byte size required $=0 \times \mathrm{F} 4$

Store $p=67=0 \times 43$

Store $q=83=0 \times 53$

Store $p$ in reg. E

Initialize reg. $D=0 \times 00$

Set contents of HL reg. pair to $0 \times 0000$

Load $q$ to reg. B

Add DE reg. pair to HL reg. pair

If LOOP12 has not been executed q times repeat LOOP12

Store higher order bits of $n$ in address C402 
LABEL

$\mathrm{C} 03 \mathrm{~F}$

$\mathrm{C} 042$

$\mathrm{C} 045$

C046

C049

$\mathrm{C} 04 \mathrm{~A}$

C04D

$\mathrm{C} 04 \mathrm{~F}$

$\mathrm{C} 050$

C051

C052

C054

$\mathrm{C} 057$

$\mathrm{C} 058$

C05B

$\mathrm{C} 05 \mathrm{C}$

$\mathrm{C} 05 \mathrm{E}$

$\mathrm{C} 061$

C062

C065

C068

C06B

$\mathrm{C} 06 \mathrm{E}$

C071

C072

$\mathrm{C} 073$

$\mathrm{C} 076$

$\mathrm{C} 077$

$\mathrm{C} 07 \mathrm{~A}$

C07B

C07E

C081

C082

$\mathrm{C} 083$

C084

$\mathrm{C} 085$

$\mathrm{C} 086$

C089

$\mathrm{C} 08 \mathrm{~A}$

$\mathrm{C} 08 \mathrm{~B}$

$\mathrm{C} 08 \mathrm{E}$

C091

$\mathrm{C} 094$

C097

C09A

C09D

C09E

C101

C102

C105

C108

C109

C10A

C10B

C10C

LOOP1

LOOP2

DONE

LOOP4

LOOP5
MNEMONICS

STA C403(H)

LDA C408(H)

MOV D, A

LDA C409(H)

MOV E, A

LOOP13

REPEAT 1

REPEAT
LXI H C40C $(\mathrm{H})$

MVI A, $00(\mathrm{H})$

MOV M, A

DCX D

MOV D, A

ORI $00(\mathrm{H})$

JZ LOOP13

INX $\mathrm{H}$

JMP LOOP1

MOV E, A

ORI $00(\mathrm{H})$

JZ LOOP2

INX $\mathrm{H}$

JMP LOOP1

LDA C406(H)

STA $\mathrm{C} 400(\mathrm{H})$

LDA $\mathrm{C} 407(\mathrm{H})$

STA C401(H)

STC

CMC

LDA C408(H)

MOV B, A

LDA C409(H)

MOV C, A

LXI H $940 \mathrm{C}(\mathrm{H})$

LXI D C40C $(\mathrm{H})$

LDAX D

MOV M, A

DCX B

MOV A, B

ORA C

JZ DONE

INX H

INX D

JMP REPEAT

LDA C404(H)

STA $\mathrm{C} 402(\mathrm{H})$

LDA C405(H)

STA $\mathrm{C} 403(\mathrm{H})$

LDA C408(H)

MOV B, A

LDA C409(H)

MOV C, A

LXI H FFFF $(\mathrm{H})$

LXI D BFFF $(\mathrm{H})$

STC

CMC

LDAX D

ADC $M$

MOV M, A
HEX CODES

32,03 .C 4

$3 \mathrm{~A}, 08, \mathrm{C} 4$

57

$3 \mathrm{~A}, 09, \mathrm{C} 4$

$5 \mathrm{~F}$

$21,0 \mathrm{C}, \mathrm{C} 4$

$3 \mathrm{E}, 00$

77

1B

57

F6, 00

$\mathrm{CA}, 5 \mathrm{~B}, \mathrm{C} 0$

23

$\mathrm{C} 3,4 \mathrm{D}, \mathrm{C} 0$

$5 \mathrm{~F}$

F6, 00

$\mathrm{CA}, 71, \mathrm{C} 0$

23

$\mathrm{C} 3,4 \mathrm{D}, \mathrm{C} 0$

$3 \mathrm{~A}, 06, \mathrm{C} 4$

$32,00, \mathrm{C} 4$

$3 \mathrm{~A}, 07, \mathrm{C} 4$

$32,01, \mathrm{C} 4$

37

$3 \mathrm{~F}$

$3 \mathrm{~A}, 08, \mathrm{C} 4$

47

$3 \mathrm{~A}, 09$, C4

$4 \mathrm{~F}$

$21,0 \mathrm{C}, 94$

$21,0 \mathrm{C}, \mathrm{C} 4$

$1 \mathrm{~A}$

77

0B

78

B1

$\mathrm{CA}, 8 \mathrm{E}, \mathrm{C} 0$

23

13

$\mathrm{C} 3,81, \mathrm{C} 0$

$3 \mathrm{~A}, 04, \mathrm{C} 4$

$32,02, \mathrm{C} 4$

$3 \mathrm{~A}, 05, \mathrm{C} 4$

$32,03, \mathrm{C} 4$

$3 \mathrm{~A}, 08$.C 4

47

$3 \mathrm{~A}, 09, \mathrm{C} 4$

$4 \mathrm{~F}$

$21, \mathrm{FF}, \mathrm{FF}$

$11, \mathrm{FF}, \mathrm{BF}$

37

$3 \mathrm{~F}$

$1 \mathrm{~A}$

$8 \mathrm{E}$

77
COMMENTS

Store lower order bits of $\mathrm{n}$ in address C403

Load higher order bits of no of max. bytes required in reg. D

Load lower order bits of no of max. bytes required in reg. E

Load memory with address of MSB

Initialize current byte to $0 \times 00$

Decrement count of no. of byte

Check if MSB of count $=0 \times 00$

If yes, go to LOOP 13

Load memory with address of next MSB

And then go to LOOP1

Check if LSB of count $=0 \times 00$

If yes, go to LOOP2

Load memory with address of next MSB

And then go to LOOP1

Store higher byte of $d$ in address C400

Store lower byte of $d$ in address C401

Reset Carry Flag

Store higher byte of max byte size in reg. B

Store lower byte of max byte size in reg. C

Point memory to MSB of copy

Point DE reg. pair to MSB of actual data

Copy current byte

Are all bytes copied?

If yes, go to DONE

Else, point memory to next MSB of copy

And point DE reg. pair to next actual MSB

And then, go to REPEAT

Store higher byte of $\mathrm{c}$ in address C402

Store lower byte of $\mathrm{c}$ in address $\mathrm{C} 403$

Store higher byte of $\max$ byte size in reg. B

Store lower byte of max byte size in reg. C

Point memory to LSB of actual data

Point DE reg. pair to LSB of copy

Reset carry flag

Add current copy byte to current actual byte with carry 


\begin{tabular}{|c|c|}
\hline C10D & \\
\hline $\mathrm{C} 10 \mathrm{E}$ & \\
\hline $\mathrm{C} 10 \mathrm{~F}$ & \\
\hline C110 & \\
\hline C113 & \\
\hline C114 & \\
\hline C115 & \\
\hline C118 & NEXT \\
\hline C11B & \\
\hline $\mathrm{C} 11 \mathrm{C}$ & \\
\hline $\mathrm{C} 11 \mathrm{~F}$ & \\
\hline C120 & \\
\hline C121 & \\
\hline C122 & \\
\hline C123 & \\
\hline C126 & \\
\hline C127 & \\
\hline $\mathrm{C} 12 \mathrm{~A}$ & \\
\hline C12B & \\
\hline $\mathrm{C} 12 \mathrm{E}$ & \\
\hline C131 & LOOP3 \\
\hline C134 & \\
\hline C135 & \\
\hline C138 & \\
\hline C139 & \\
\hline C13A & \\
\hline C13B & \\
\hline C13C & \\
\hline C13F & \\
\hline C140 & \\
\hline C143 & \\
\hline C144 & \\
\hline C147 & \\
\hline C14A & LOOP8 \\
\hline C14B & \\
\hline $\mathrm{C} 14 \mathrm{C}$ & \\
\hline $\mathrm{C} 14 \mathrm{~F}$ & \\
\hline C150 & \\
\hline C153 & \\
\hline C154 & \\
\hline C157 & \\
\hline C158 & \\
\hline C15B & \\
\hline C15C & \\
\hline $\mathrm{C} 15 \mathrm{~F}$ & \\
\hline C160 & \\
\hline C161 & \\
\hline C162 & \\
\hline C163 & \\
\hline C164 & \\
\hline C165 & \\
\hline C166 & \\
\hline C167 & \\
\hline C168 & LOOP6 \\
\hline C169 & \\
\hline C16A & \\
\hline
\end{tabular}

\begin{tabular}{|c|c|c|}
\hline MNEMONICS & HEX CODE & COMMENTS \\
\hline DCX B & $0 \mathrm{~B}$ & \\
\hline MOV A, B & 78 & \\
\hline ORA C & B1 & Are all bytes added? \\
\hline JZ NEXT & $\mathrm{CA}, 18, \mathrm{C} 1$ & If yes, go to NEXT \\
\hline DCX H & $2 \mathrm{~B}$ & Else, point memory to next actual LSB \\
\hline DCX B & $1 \mathrm{~B}$ & And point DE reg pair to next copy LSB \\
\hline JMP LOOP5 & $\mathrm{C} 3,0 \mathrm{~A}, \mathrm{C} 1$ & And then, go to LOOP5 \\
\hline LDA $\mathrm{C} 402(\mathrm{H})$ & $3 \mathrm{~A}, 02, \mathrm{C} 4$ & \\
\hline MOV D, A & 57 & \\
\hline LDA C403(H) & $3 \mathrm{~A}, 03, \mathrm{C} 4$ & \\
\hline MOV E, A & $5 \mathrm{~F}$ & $\mathrm{D}-\mathrm{E}=$ count of $\mathrm{c}$ \\
\hline DCX D & $1 \mathrm{~B}$ & Decrement D-E reg. pair \\
\hline MOV A,D & $7 \mathrm{~A}$ & \\
\hline ORA E & B3 & Is $\mathrm{D}-\mathrm{E}=0 \times 0000 ?$ \\
\hline JZ LOOP3 & $\mathrm{CA}, 13, \mathrm{C} 1$ & If yes, go to LOOP3 \\
\hline MOV A,D & $7 \mathrm{~A}$ & Else, count of $c=$ new $D-E$ \\
\hline STA $\mathrm{C} 402(\mathrm{H})$ & $32,02, \mathrm{C} 4$ & \\
\hline MOV ,E & $7 \mathrm{~B}$ & \\
\hline STA C403(H) & $32,03, \mathrm{C} 4$ & \\
\hline JMP LOOP4 & $\mathrm{CA}, 9 \mathrm{~A}, \mathrm{C} 0$ & And then go to LOOP4 \\
\hline LDA $\mathrm{C} 400(\mathrm{H})$ & $3 \mathrm{~A}, 00, \mathrm{C} 4$ & \\
\hline MOV D, A & 57 & \\
\hline LDA C401(H) & $3 \mathrm{~A}, 01, \mathrm{C} 4$ & \\
\hline MOV E, A & $5 \mathrm{~F}$ & $\mathrm{D}-\mathrm{E}=\operatorname{count}$ of $\mathrm{d}$ \\
\hline DCX D & 1B & Decrement count of $d$ \\
\hline MOV A,D & $7 \mathrm{~A}$ & \\
\hline ORA E & B3 & Is $\mathrm{D}-\mathrm{E}=0 \times 0000 ?$ \\
\hline JZ LOOP8 & $\mathrm{CA}, 4 \mathrm{~A}, \mathrm{C} 1$ & If yes, go to LOOP8 \\
\hline MOV D, A & 57 & Else, update value of $d-$ count \\
\hline STA $\mathrm{C} 400(\mathrm{H})$ & $32,00, \mathrm{C} 4$ & \\
\hline MOV E, A & $5 \mathrm{~F}$ & \\
\hline STA $\mathrm{C} 401(\mathrm{H})$ & $32,01, \mathrm{C} 4$ & \\
\hline JMP REPEAT1 & $\mathrm{C} 3,7 \mathrm{~B}, \mathrm{C} 0$ & And then, go to REPEAT1 \\
\hline STC & 37 & \\
\hline CMC & $3 \mathrm{~F}$ & Reset Carry flag \\
\hline LDA $\mathrm{C} 408(\mathrm{H})$ & $3 \mathrm{~A}, 08, \mathrm{C} 4$ & \\
\hline MOV B, A & 47 & Load MSB of max bit size in reg. $B$ \\
\hline LDA C409(H) & $3 \mathrm{~A}, 09, \mathrm{C} 4$ & \\
\hline MOV C, A & $4 \mathrm{~F}$ & Load LSB of $\max$ bit size in reg. C \\
\hline LDA C402(H) & $3 \mathrm{~A}, 02, \mathrm{C} 4$ & \\
\hline MOV D, A & 57 & Load MSB of $n$ in $r e g . ~ D$ \\
\hline LDA C403(H) & $3 \mathrm{~A}, 03, \mathrm{C} 4$ & \\
\hline MOV E, A & $5 \mathrm{~F}$ & Load LSB of $n$ in $r e g$. $E$ \\
\hline LXI H FFFF $(\mathrm{H})$ & $21, \mathrm{FF}, \mathrm{FF}$ & Load address of LSB to memory \\
\hline MOV A,M & $7 \mathrm{E}$ & Load A with data that memory points to \\
\hline SUB E & 93 & Subtract LSB of $n$ from this data \\
\hline MOV M, A & 77 & Update value of LSB \\
\hline DCX B & oB & Indicates that LSB has been updated \\
\hline DCX H & $2 \mathrm{~B}$ & Point memory to next LSB \\
\hline MOV A, M & $7 \mathrm{E}$ & Load A with data that memory points to \\
\hline SBB D & $9 \mathrm{~A}$ & $\begin{array}{l}\text { Subtract MSB of } n \text { from this data with } \\
\text { borrow }\end{array}$ \\
\hline MOV M, A & 77 & Update value of second LSB \\
\hline DCX B & oB & Indicates that second LSB has been updated \\
\hline DCX H & $2 \mathrm{~B}$ & Point memory to next LSB \\
\hline MOV A,M & $7 \mathrm{E}$ & \\
\hline SBI $00(\mathrm{H})$ & DF, 00 & $\begin{array}{l}\text { Subtract } 0 \times 00 \text { from current byte with } \\
\text { borrow }\end{array}$ \\
\hline
\end{tabular}




\begin{tabular}{|c|c|c|c|c|}
\hline & LABEL & MNEMONICS & HEX CODE & COMMENTS \\
\hline $\mathrm{C} 16 \mathrm{C}$ & & MOV M, A & 77 & \\
\hline C16D & & DCX B & oB & Indicates that current byte is updated \\
\hline C16E & & MOV A, B & 78 & \\
\hline $\mathrm{C} 16 \mathrm{~F}$ & & ORI $\quad 00(\mathrm{H})$ & $\mathrm{F} 6,00$ & Check if MSB of count is $0 \times 00$ \\
\hline C171 & & JZ LOOP15 & $\mathrm{CA}, 77, \mathrm{C} 1$ & If yes, go to LOOP 15 \\
\hline C174 & & JMP LOOP6 & $\mathrm{C} 3,68, \mathrm{C} 1$ & If not, go to LOOP6 \\
\hline C177 & LOOP15 & MOV A, C & 79 & \\
\hline $\mathrm{C} 178$ & & ORI $\quad 00(\mathrm{H})$ & F6, 00 & Check if LSB of count is $0 \times 00$ \\
\hline C17A & & JZ LOOP7 & $\mathrm{CA}, 80, \mathrm{C} 1$ & If yes, go to LOOP15 \\
\hline C17D & & JMP LOOP6 & $\mathrm{C} 3,68, \mathrm{C} 1$ & If not, go to LOOP6 \\
\hline $\mathrm{C} 180$ & LOOP7 & LDA $\mathrm{C} 408(\mathrm{H})$ & $3 \mathrm{~A}, 08, \mathrm{C} 4$ & \\
\hline C183 & & MOV B, A & 47 & Load MSB of max bit size to reg. B \\
\hline C184 & & LDA C409(H) & $3 \mathrm{~A}, 09, \mathrm{C} 4$ & \\
\hline C187 & & MOV C, A & $4 \mathrm{~F}$ & Load LSB of max bit size to reg. C \\
\hline C188 & & MOV A, C & 79 & \\
\hline C189 & & SUI $02(\mathrm{H})$ & D6,02 & Subtract $0 \times 02$ from LSB of $\max$ bit size \\
\hline $\mathrm{C} 18 \mathrm{~B}$ & & MOV C,A & $4 \mathrm{~F}$ & Update value of this LSB \\
\hline $\mathrm{C} 18 \mathrm{C}$ & & MOV A, B & 78 & \\
\hline $\mathrm{C} 18 \mathrm{D}$ & & SBI $\quad 00(\mathrm{H})$ & DF, 00 & $\begin{array}{l}\text { Subtract } 0 \times 00 \text { from MSB of max bit size with } \\
\text { borrow }\end{array}$ \\
\hline $\mathrm{C} 18 \mathrm{~F}$ & & MOV B, A & 47 & Update value of this MSB \\
\hline C190 & & LXI H C40C $(\mathrm{H})$ & $21,0 \mathrm{C}, \mathrm{C} 4$ & Load address with MSB of data bytes \\
\hline C193 & LOOP9 & MOV A,M & $7 \mathrm{E}$ & \\
\hline C194 & & $\mathrm{CPI} \quad 00(\mathrm{H})$ & $\mathrm{FE}, 00$ & Compare current value of byte with $0 \times 00$ \\
\hline C196 & & JNZ LOOP8 & $\mathrm{C} 2,4 \mathrm{~A}, \mathrm{C} 1$ & If not true, go to LOOP8 \\
\hline C199 & & DCX B & $0 \mathrm{~B}$ & Indicates that current byte is compared \\
\hline $\mathrm{C} 19 \mathrm{~A}$ & & MOV A, B & 78 & \\
\hline $\mathrm{C} 19 \mathrm{~B}$ & & ORI $\quad 00(\mathrm{H})$ & $\mathrm{F} 6,00$ & Check if MSB of count is $0 \times 00$ \\
\hline C19D & & JZ LOOP16 & $\mathrm{CA}, 04, \mathrm{C} 2$ & If yes, go to LOOP 16 \\
\hline C200 & & INX H & 23 & Else if not, point memory to next MSB \\
\hline C201 & & JMP LOOP9 & $\mathrm{C} 3,93, \mathrm{C} 1$ & And go to LOOP9 \\
\hline $\mathrm{C} 204$ & LOOP16 & MOV A, C & 79 & \\
\hline C205 & & ORI $\quad 00(\mathrm{H})$ & $\mathrm{F} 6,00$ & Check if LSB of count is $0 \times 00$ \\
\hline $\mathrm{C} 207$ & & JZ LOOP10 & $\mathrm{CA}, 0 \mathrm{E}, \mathrm{C} 2$ & If yes, go to LOOP 10 \\
\hline $\mathrm{C} 20 \mathrm{~A}$ & & INX H & 23 & Else if no, point memory to next MSB \\
\hline $\mathrm{C} 20 \mathrm{~B}$ & & JMP LOOP9 & $\mathrm{C} 3,93, \mathrm{C} 1$ & And go to LOOP9 \\
\hline $\mathrm{C} 20 \mathrm{E}$ & LOOP10 & INX H & 23 & \\
\hline $\mathrm{C} 20 \mathrm{~F}$ & & MOV A,D & $7 \mathrm{~A}$ & \\
\hline $\mathrm{C} 210$ & & CMP M & $\mathrm{BE}$ & $\begin{array}{l}\text { Compare value at second LSB with that of } \\
\text { MSB of } n\end{array}$ \\
\hline $\mathrm{C} 211$ & & JZ LOOP11 & $\mathrm{CA}, 1 \mathrm{~A}, \mathrm{C} 2$ & If equal, go to LOOP 11 \\
\hline $\mathrm{C} 214$ & & JC LOOP8 & $\mathrm{DA}, 4 \mathrm{~A}, \mathrm{C} 1$ & Else if greater, go to LOOP8 \\
\hline $\mathrm{C} 217$ & & JMP LOOP12 & $\mathrm{C} 3,2 \mathrm{D}, \mathrm{C} 2$ & Else if lesser, terminate the program \\
\hline $\mathrm{C} 21 \mathrm{~A}$ & LOOP11 & INX H & 23 & \\
\hline C21B & & MOV A, E & $7 \mathrm{~B}$ & \\
\hline $\mathrm{C} 21 \mathrm{C}$ & & CMP M & $\mathrm{BE}$ & $\begin{array}{l}\text { Compare value LSB of } n \text { with that at address } \\
\text { FFFF }\end{array}$ \\
\hline C21D & & JC LOOP8 & $\mathrm{DA}, 4 \mathrm{~A}, \mathrm{C} 1$ & If lesser, go to LOOP8 \\
\hline $\mathrm{C} 220$ & & JNZ LOOP12 & $\mathrm{C} 2,2 \mathrm{D}, \mathrm{C} 2$ & Else If not equal, terminate the program \\
\hline $\mathrm{C} 223$ & & MVI A,00(H) & $3 \mathrm{E}, 00$ & Else if equal, execute lines $157-161$ \\
\hline $\mathrm{C} 225$ & & STA FFFE $(\mathrm{H})$ & $32, \mathrm{FE}, \mathrm{FF}$ & Store $0 \times 00$ at address FFFE \\
\hline $\mathrm{C} 228$ & & MVI $00(\mathrm{H})$ & $3 \mathrm{E}, 00$ & \\
\hline $\mathrm{C} 22 \mathrm{~A}$ & & STA FFFF $(H)$ & $32, \mathrm{FF}, \mathrm{FF}$ & Store $0 \times 00$ at address FFFF \\
\hline $\mathrm{C} 22 \mathrm{D}$ & LOOP12 & HLT & 76 & \\
\hline
\end{tabular}

After running the above code, the required message data $m$ is stored at address locations FFFE (MSB) and FFFF (LSB). 


\section{Utilizing random primes for encrypting long data byte-wise}

Till now, we considered the transmission of only one byte of data from the sender to the receiver. In practice however, this will not be the case. Usually multiple data bytes are send in one transmission. While using a single encryption key for all the bytes also works pretty well if the key size is quite big, the strength of encryption increases by leaps and bounds if random set of prime numbers $p$ and $q$ are chosen for every byte of data. For this, we'll have to generate random primes for encrypting each byte of data. In this section we will take following approach:

1. Store a set of known prime numbers in a certain array of memory locations.

2. Randomly choose two prime numbers to set as $p$ and $q$ respectively.

3. Choose a suitable value of $e$ which is co-prime which $\phi(n)=(p-1)(q-1)$

4. Choose a suitable value for $d$ from eq. 2.03 .

In the previous example, we used $e=17$. Consequently, we observed that at least 17 bytes were required to do the calculations in eq. 2.04 in the sender's microprocessor. Also $p$ and $q$ were chosen as 67 and 83 respectively. This meant that the cipher text would be atleast 15348 bytes long, depending on the message $m$ transmitted. We wish to utilize the codes given in section 3.1 and 3.2 in cycles for encrypting each byte of message data $m$. But to do so, we should ensure that the number of bytes required for new values of $p$, $q$ (which are randomly chosen), $d$ and $e$ (which are chosen on the basis of $p$ and $q$ ) do no require more bytes for calculations than the ones that are already implemented. So, we impose that $p$ and $q$ should only be primes starting from 17 to 67 . Also we impose that $e=17$ The reasons for these are as follows:

1. The lower bound 17 is chosen because it is mandatory that $n$ be greater than the message byte. Since the maximum decimal value of the message byte is $256, \min (p) \min (q)>256$. It turns out that the least value of a prime integer $h$ such that $h^{2}>256$ is $h=17$ and hence the value of lower bound is chosen to be 17 .

2. In the example dealt with previously $c$ was maximum 2 bytes long, this is because $n=5561=0 \times 15 \mathrm{~B} 9$ is 2 bytes long (see eq. 2.04). There we had chosen $p=67$ and $q=83$. So, for any prime numbers $p$ and $q$ such that $\max (p)=\max (p)=67$ would imply that $\max (p q)<5561$ and hence would still be at most 2 bytes long.

3. In the previous example $e$ was chosen to be as 17. For the next example (which includes utilizing random prime numbers), we keep this value unchanged. The only restriction on the value of $e$ is it should be co-prime with $\phi(n)=(p-1)(q-1)$. For $e=17$, if this were not so, it would imply that atleast one of $(p-1)$ or $(q-1)$ is of the form $17 l$ where $l \in \mathbb{Z}^{+}$(because the only factor of 17 other than 1 is 17). This implies that either $p$ or $q$ (or both) is of the form $17 l+1$. Fortunately, primes of such form does not exists between our interval choice of $17-67$. Hence, the choice $e=17$ for any set $\{p, q\}$.

4. In the previous example $d$ was chosen to be 9869. The equation solved for the same is eq. 2.03. It turns out that a general form of the solution for this equation is $x \phi(n)+y$ such that $x \in \mathbb{Z}^{+} \cup\{0\}$ and $y \in\{1,2, \cdots \phi(n)-1\}$. For the next example (including random primes) we'll choose $x=0$. This implies that $1 \leq d \leq \phi(n)-1$. In the previous example $\phi(n)$ was equal to 5412 which is a 2 byte number. So, using this choice, $d$ would also be of atmost 2 bytes (just the way it was in previous example: $d=9869=0 \times 268 \mathrm{D}$ ).

5. In the previous example, we saw in section 2.4 , that $\max (c)=n-1=5560$. For our next example, it will be $\max (n)-1=\max (p) \max (q)-1=67 \times 67-1=4488$. Also

$\max (d)=\max (\phi(n)-1)=(\max (p)-1)(\max (q)-1)-1=(67-1)(67-1)-1=4355$. This implies $\max \left(c^{d}\right)=\max (c)^{\max (d)}=4488^{4355}$, which is less that the value $5560^{9869}$ obtained in the previous example. Hence, considering that the cipher text generated will be atleast 15348 bytes long is a safe assumption. Therefore, we can make use of the code written in section 3.2 directly in a cyclic manner to decrypt the long message data which includes multiple number of bytes. 


\subsection{Choosing random primes}

As described above, the purpose of this section is to not generate random primes, but randomly choose a certain prime from a list of prime numbers. There are 13 primes numbers between 17 and 67 (both inclusive). So, we will use the following approach.

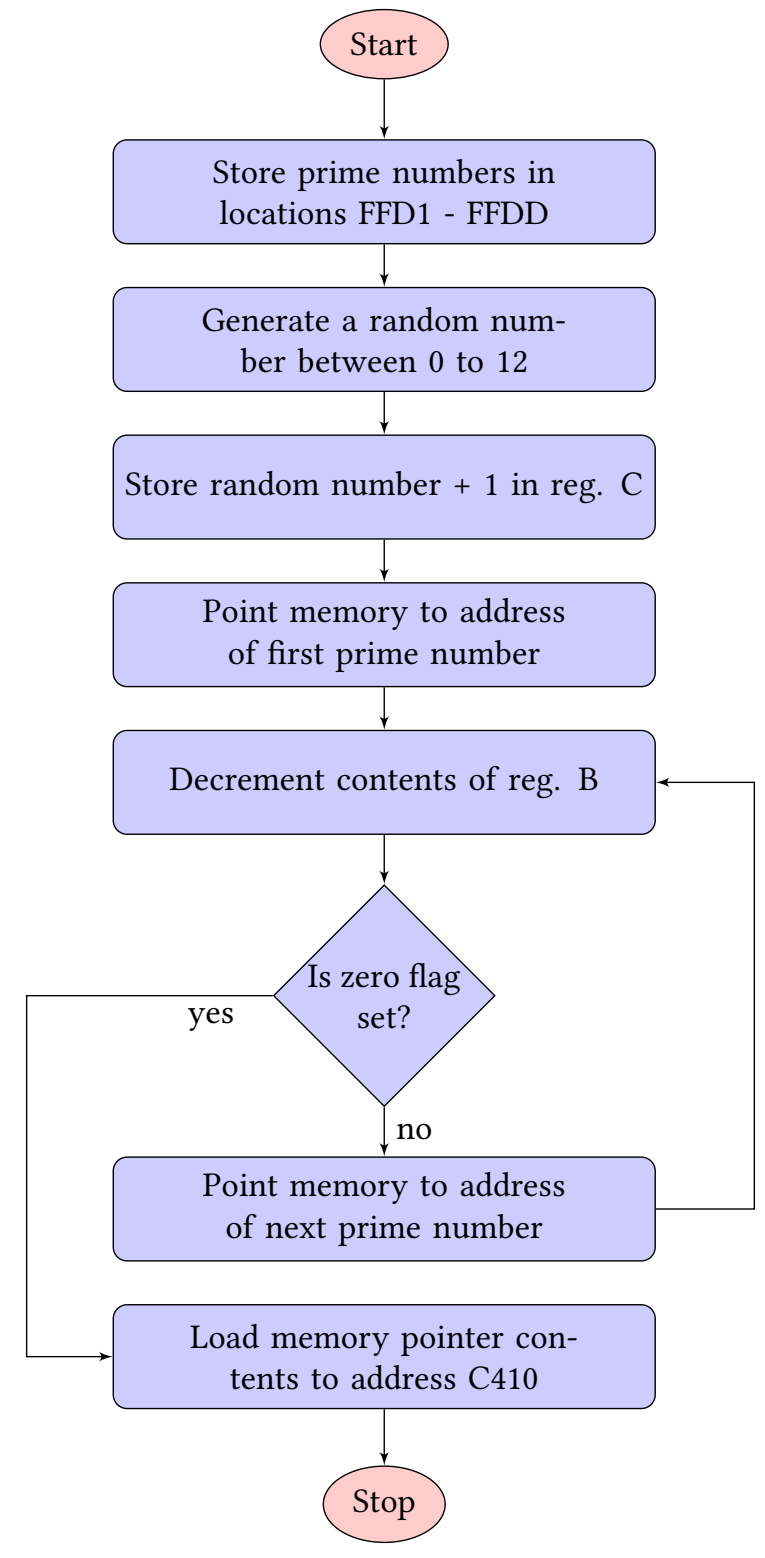

Figure 3: Algorithm for choosing random prime numbers

In the above algorithm, step two indicates that a random number has to be generated between 0 and 12 . We will achieve this using the Linear Congruential Generator (LCG) of random numbers. LCG is an algorithm with generates a sequence of pseudo random numbers with following recurrence relation:

$$
X_{n+1}=\left(A X_{n}+C\right) \bmod M \longrightarrow(\text { eq.4.01) }
$$

where $X$ is the sequence of pseudo random numbers, $A$ is called the multiplier, $C$ is called the increment and $M$ is called the modulus.

When the values of $A, C$ and $M$ are sufficiently large, this method will generate a good uniform distribution of pseudo random numbers in the range $\{0,1, \cdots, M-1\}$. To restrict the numbers to the set $\{0,1, \cdots, 12\}$, we will take the remainder of the numbers thus generated upon divison by the number 13 , i.e.

$$
I_{n}=X_{n} \bmod 13 \longrightarrow \text { (eq.4.02) }
$$

where $I_{n}$ is the random number which would serve as the random index for our array of primes. Some choices of $A, B$ and $M$ is commonly used by various compilers for generating random numbers. For this project, we will use the choice made by Numerical Recipes i.e. $M=2^{32}=0 \times 100000000, A=1664525=0 \times 19660 \mathrm{D}$ (three bytes) and $C=1013904223=0 \times 3 \mathrm{C} 6 \mathrm{EF} 35 \mathrm{~F}$ ( 4 bytes). The flowchart for generating $I_{n}$ is given below: 


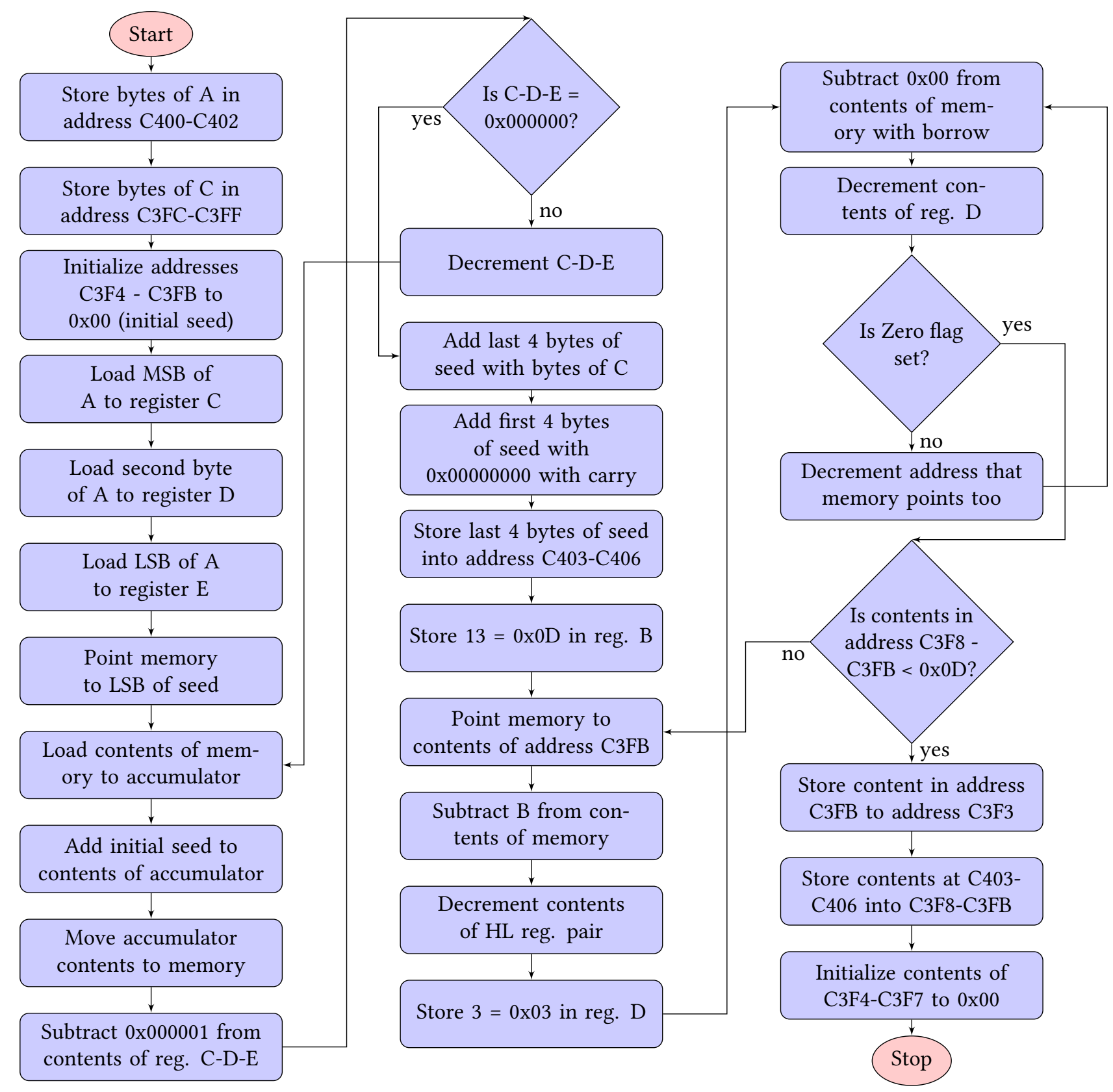

Figure 4: Flowchart for generating random numbers between 0-12 (inclusive)

In this example, $X_{n}$ will always be a 4 byte data owing to the fact that the choice of $M=2^{32}=0 \times 100000000$. Also A is chosen to be $1664525=0 x 19660 \mathrm{D}$ i.e. a 3 byte data. Therefore $A . X_{n}$ is atmost of 7 bytes. Also $C$ is chosen to be $1013904223=0 \times 3 C 6 \mathrm{EF} 35 \mathrm{~F}$ i.e. a 8 byte data. Hence, $A . X_{n}+C$ is atmost of 8 bytes. This is why 8 address locations have been allotted for storing the initial value of the seed (C3F4- $\mathrm{C} 3 \mathrm{FB})$. It does not mean that the seed is of 8 bytes, this has been introduced just for ease of arithmetic. Initially the first foure bytes will always be set to $0 x 00$. The modulo with $M$ of $A . X_{n}+C$ does not need to be explicitly computed, because the choice of $M$ suggests that the result will be the last four bytes of the result $A . X_{n}+C$. The final result $I_{n}$ is stored in address C3F3 (as shown in the third last step of the above flowchart). Thereafter, new value of seed $X_{n+1}$ that is obtained is substituted in place of the initial seed $X_{n}$. For find the next seed, whole flowchart from step 4 to the end needs to be executed again.

\subsection{5 program for generating random numbers between 0-12 (inclusive)}

Note that in the subsequent codes, we will not display the address of the program counter or the hex codes, because they are just sub-codes which will all be used together when we implement the final program in section 6 . There are the necessary data will be given. Using the flowchart given in Figure 4, the program for generating random integers between 0 and 12 (both inclusive) is given below: 
LABEL

STARTRAND

SET1

SET2

ANOTHER

LOOP14
MNEMONICS

MVI A, 19 (H)

STA C400(H)

MVI A, $66(\mathrm{H})$

STA C401(H)

MVI A,0D(H)

STA C402(H)

MVI A, $3 \mathrm{C}(\mathrm{H})$

STA C3FC $(\mathrm{H})$

MVI A, $6 \mathrm{E}(\mathrm{H})$

STA C3FD $(\mathrm{H})$

MVI A, F3 (H)

STA C3FE $(\mathrm{H})$

MVI A, $5 \mathrm{~F}(\mathrm{H})$

STA C3FF $(\mathrm{H})$

MVI C,08(H)

LXI H C3F4 $(\mathrm{H})$

MVI A, $00(\mathrm{H})$

MOV M, A

DCR C

JZ SET2

INX H

JMP SET1

LDA C3F8 $(\mathrm{H})$

STA C403(H)

LDA C3F9 $(\mathrm{H})$

STA C404(H)

LDA C3FA $(\mathrm{H})$

STA C405(H)

LDA C3FB (H)

STA C406(H)

LDA C400(H)

MOV C, A

LDA C401(H)

MOV D, A

LDA C402(H)

MOV E, A

LXI H C3FB (H)

LDA C406(H)

ADD $M$

MOV M, A

DCX $\mathrm{H}$

LDA C405(H)

ADC $M$

MOV M, A

DCX $\mathrm{H}$

LDA C404(H)

ADC $M$

MOV M, A

DCX $\mathrm{H}$

LDA C403(H)

ADC $M$

MOV M, A

DCX $\mathrm{H}$

MVI B, $04(\mathrm{H})$
COMMENTS

Store MSB of A

Store second byte of A

Store LSB of A

Store MSB of C

Store second MSB of C

Store second LSB of C

Store LSB of C

Set initial seed $=0 \times 00000000$

Copy 5 th byte of seed

Copy 6 th byte of seed

Copy 7 th byte of seed

Copy 8 th byte (LSB) of seed

Store MSB of A in reg. C

Store second byte of $A$ in reg. D

Store LSB of A in reg. E

Point memory to LSB of seed

Add LSB of initial seed to current memory Update value of current byte

Point memory to second LSB of seed

Add second LSB of initial seed to memory with c arry

Update value of current byte

Point memory to third LSB of seed

Add third LSB of initial seed to memory with carry

Update value of current byte

Point memory to fourth LSB of seed

Add fourth LSB of initial seed to memory with carry

Update value of current byte

Point memory to next LSB of seed

Initialize reg. B to $04(\mathrm{H})$ 
LABEL

LOOP26

LOOP17

LOOP16
MNEMONICS

MOV A,M

ACI $00(\mathrm{H})$

MOV M, A

DCR B

JZ LOOP25

DCX H

JMP LOOP26

LOOP25 MOV A, E

SUI $01(\mathrm{H})$

MOV E, A

MOV A, D

SBI $00(\mathrm{H})$

MOV D, A

MOV A,C SBI $00(\mathrm{H})$

MOV C, A

MOV A, C

ORA D

JZ LOOP13

JMP LOOP14

LOOP13 MOV A, E

CPI $00(\mathrm{H})$

JZ LOOP15

JMP LOOP14

LOOP15 LXI H, C3FB $(\mathrm{H})$

LDA $\mathrm{C} 3 \mathrm{FF}(\mathrm{H})$

ADD $M$

MOV M, A

DCX $\mathrm{H}$

LDA C3FE $(\mathrm{H})$

ADC $M$

MOV M, A

DCX H

LDA C3FD

ADC $M$

MOV M, A

DCX H

LDA C3FC

ADC $M$

MOV M, A

DCX H

MVI B , $04(\mathrm{H})$

ACI $00(\mathrm{H})$

MOV M, A

DCR B

JZ LOOP16

DCX H

JMP LOOP17
COMMENTS

Add $0 \times 00$ to current seed byte with carry Update value of current byte Indicates that current byte has been updated If all bytes of seed are updated, go to LOOP25 Else, point memory to next LSB of seed And then go to LOOP26

Subtract $0 \times 01$ from reg. E

Subtract $0 \times 00$ from reg. D with borrow

Subtract $0 \times 00$ from reg. C with borrow

Is reg. $C=$ reg. $D=0 \times 00$ ?

If yes, go to LOOP 13

If not, go to LOOP 14

Is $\mathrm{reg} . \mathrm{E}=0 \mathrm{x} 00$ ?

If yes, go to LOOP 15

If not, go to LOOP 14

Point memory to LSB of seed

Add LSB of C to LSB of seed

Point memory to second LSB of seed

Add second LSB of C to second LSB of seed with carry

Point memory to third LSB of seed

Add second LSB of C to second LSB of seed with carry

Point memory to third LSB of seed

Add second LSB of C to third LSB of seed with carry

Point memory to third fourth of seed

Set reg. $B=0 \times 04$

Add $0 \times 00$ to current byte of seed Indicates that current seed byte is updated If all seed bytes are updated go to LOOP 16 If not, point memory to next LSB of seed And then go to LOOP17

Store MSB of seed in address C403

Store second MSB of seed in address C404

Store second LSB of seed in address C405 
LABEL

110

111

112

113

114

115

116

117

118

119

120

121

122

123

124

125

126

127

128

129

130

131

132

133

134

135

136

137

138

139

140

141

142

143

144

145

146

147

148

149

150

151

152

153

154

155

156

157
MNEMONICS

STA C406(H)

MVI B,$\quad 0 \mathrm{D}(\mathrm{H})$

LOOP21 LXI H C3FB $(\mathrm{H})$

MOV A,M

SUB B

MOV M, A

DCX $\mathrm{H}$

MVI D,03(H)

LOOP19

MOV A,M

SBI $00(\mathrm{H})$

MOV M, A

DCR D

JZ LOOP18

DCX H

JMP LOOP19

LOOP18 LXI H, C3FB $(\mathrm{H})$

MOV A,M

INX $\mathrm{H}$

ORA $M$

JZ LOOP20

JMP LOOP21

LOOP20

INX $\mathrm{H}$

MOV A,M

CPI $00(\mathrm{H})$

JZ LOOP22

JMP LOOP21

LOOP22 INX H

MOV A,M

CMP B

JZ LOOP23

JC LOOP24

JMP LOOP21

LOOP23 MVI A,00(H)

MOV M, A

LOOP24 LDA C3FB $(\mathrm{H})$

STA C3F3 $(\mathrm{H})$

MVI A, $00(\mathrm{H})$

STA C3F $4(\mathrm{H})$

MVI A, $00(\mathrm{H})$

STA C3F5 (H)

MVI A, $00(\mathrm{H})$

STA C3F6 $(\mathrm{H})$

MVI A, $00(\mathrm{H})$

STA C $3 F 7(\mathrm{H})$

LDA C403(H)

STA $\mathrm{C} 3 \mathrm{~F} 8(\mathrm{H})$

LDA C $404(\mathrm{H})$

STA C3F9 $(\mathrm{H})$

LDA C $405(\mathrm{H})$

STA C3FA $(\mathrm{H})$

LDA C406(H)

STA C3FB $(\mathrm{H})$

RET
COMMENTS

Store LSB of seed in address C406

Store $13=0 \times 0 D$ in $\mathrm{reg}$. B

Point memory to LSB of seed

Subtract reg. B from LSB of seed

Go to next LSB of seed

Store $0 \times 03$ in reg. D

Subtract $0 \times 00$ from current byte of seed with borrow

Indicates that current seed byte is updated

If all seed bytes are updated go to LOOP18

If not, point memory to next LSB of seed byte

And then go to LOOP19

Point memory to MSB of 4-byte seed

Load memory contents in accumulator

Point memory to second MSB of seed

Are both MSB and second MSB of seed $=0 \times 00$ ?

If yes, go to LOOP20

If not, go to LOOP21

Point memory to second LSB of seed

Compare second LSB of seed byte with $0 \times 00$

If they are equal, go to LOOP22

Else, go to LOOP21

Point memory of LSB of 4-byte seed

Load this byte to accumulator

Compare this byte with contents of reg. B

If they are equal go to LOOP23

If byte is less than $0 x 0 \mathrm{D}$, go to LOOP24

Else, go to LOOP21

Set LSB of seed to $0 \times 00$

Store mod 13 random no. in address C3F3

Set byte 1 of next initial seed to $0 \times 00$

Set byte 2 of next initial seed to $0 \times 00$

Set byte 3 of next initial seed to $0 \times 00$

Set byte 4 of next initial seed to $0 \times 00$

Set byte 5 of next initial seed to MSB of the 4-byte new seed generated

Set byte 6 of next initial seed to second MSB of the 4-byte new seed generated

Set byte 7 of next initial seed to second LSB of the 4-byte new seed generated

Set byte 8 (LSB) of next initial seed to LSB of the 4-byte new seed generated 
One run of the code above will create a random number between 0 and 12 (inclusive) in the address location C3F3. To generate another random number run the code from label ANOTHER to RET again.

\subsection{5 program for choosing random primes}

As mentioned in the beginning of section 4, the approach we will take for choosing random primes in this paper is by first storing an array of prime numbers in some memory locations. Then generate a random number which will serve as the index in the list of prime numbers. The prime number whose index matches with the the random number generated (between $0-12$ ) will be chosen for encryption. A pair of primes will be selected for every byte of data by utilizing the program given in section 4.2 .

LABEL CHOOSE

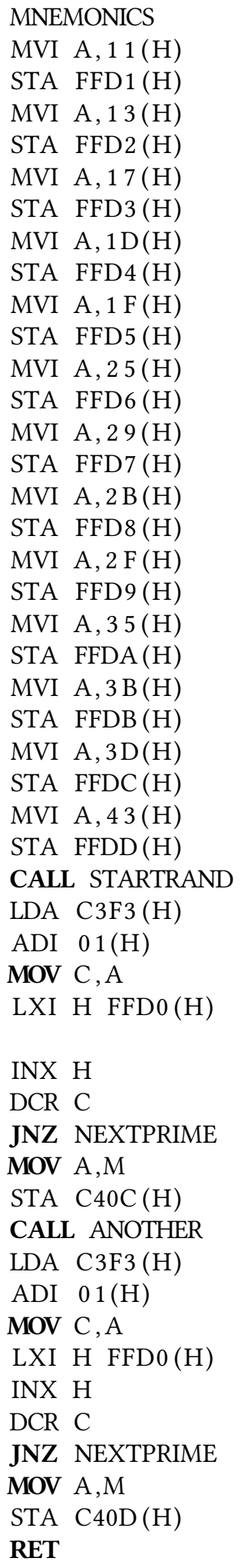

COMMENTS

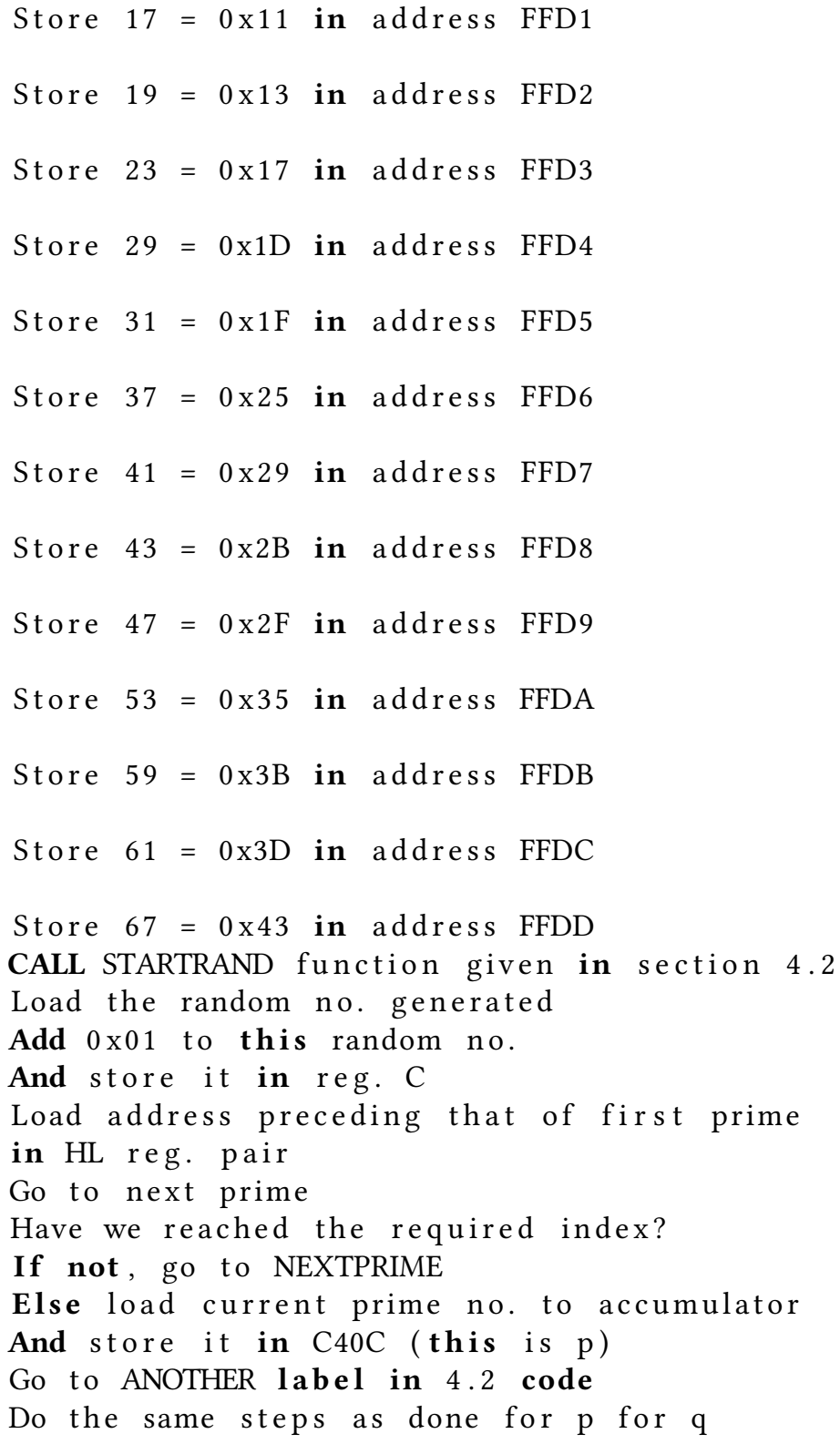




\section{Choose value of public and private key exponent for random primes}

We have discussed how to set random values for $p$ and $q$ in section 4. Now, we'll have to set suitable values of $d$ (private key exponent) and $e$ (public key exponent). As mentioned in the beginning of section 4 , we will impose $e=17=0 \times 11$ and $d$ is some integer such that $1 \leq d \leq \phi(n)-1$. The flowchart for deciding $d$ is given below:

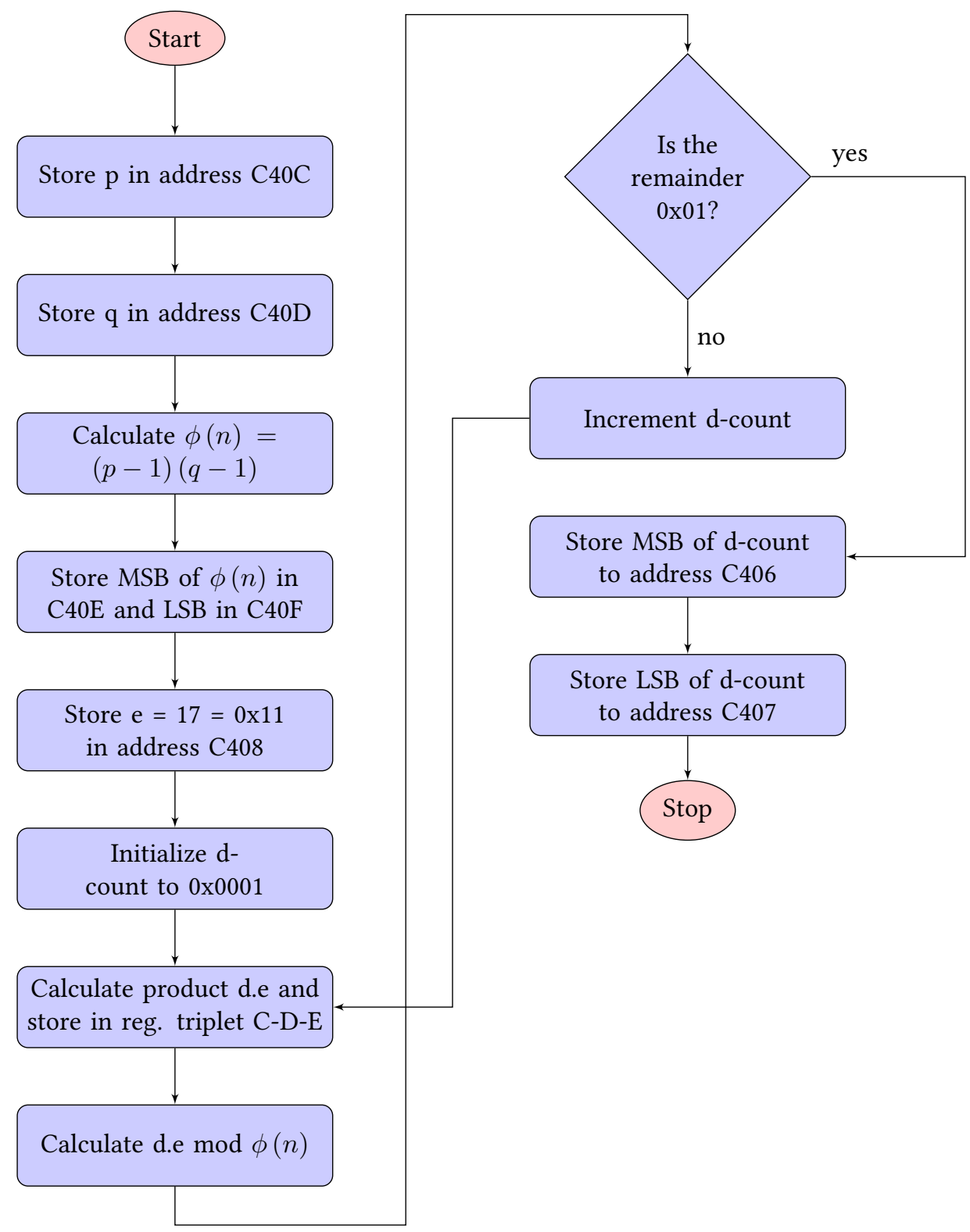

Figure 5: Flowchart for deciding private key exponent

Note that in this program, $e$ is of 1 byte and $d$ is of 2 bytes. Hence, the product $d . e$ is atmost 3 bytes. This is why the register triplet $\mathrm{C}$-D-E is used for all the arithmetic calculations. The 8085 program of the above flowchart for $p=23=0 \times 17$ and $q=47=0 \times 2 \mathrm{~F}$ is implemented below: 
LABEL

\section{MNEMONICS}

MVI A,17(H)

STA $\mathrm{C} 40 \mathrm{C}(\mathrm{H})$

MVI A, $2 \mathrm{~F}(\mathrm{H})$

STA C40D $(\mathrm{H})$

LDA $\mathrm{C} 40 \mathrm{C}(\mathrm{H})$

SUI $01(\mathrm{H})$

MOV C, A

MVI B, $00(\mathrm{H})$

LDA C40D (H)

SUI $01(\mathrm{H})$

MOV E, A

MVI D, $00(\mathrm{H})$

LXI H $0000(\mathrm{H})$

LOOP28

LOOP27

LOOP32

LOOP30
DAD B

DCX D

MOV D, A

ORA E

JZ LOOP27

JMP LOOP28

MOV A, H

STA C40E $(\mathrm{H})$

MOV A, L

STA $\mathrm{C} 40 \mathrm{~F}(\mathrm{H})$

MVI A, 11(H)

STA $\mathrm{C} 408(\mathrm{H})$

MVI A, $00(\mathrm{H})$

STA $\mathrm{C} 410(\mathrm{H})$

MVI A, $01(\mathrm{H})$

STA C411(H)

STC

CMC

MVI C, $00(\mathrm{H})$

MVI D, $00(\mathrm{H})$

MVI E, $00(\mathrm{H})$

LDA C408(H)

MOV B, A

LDA $\mathrm{C} 410(\mathrm{H})$

STA $\mathrm{C} 412(\mathrm{H})$

LDA C411(H)

STA $\mathrm{C} 413(\mathrm{H})$

MOV A, E

ADD B

MOV E, A

MOV A,D

ACI $00(\mathrm{H})$

MOV D, A

MOV A, C

ACI $00(\mathrm{H})$

MOV C, A

LDA C412(H)

MOV $\mathrm{H}, \mathrm{A}$

LDA $\mathrm{C} 413(\mathrm{H})$

MOV L, A

DCX $\mathrm{H}$

MOV A, H

ORA L

JZ LOOP29
COMMENTS

Store $p=23=0 \times 17$ in address $\mathrm{C} 40 \mathrm{C}$

Store $q=47=0 \times 2 F$ in address $C 40 D$

Store $\mathrm{p}-1$ in $\mathrm{reg}$. C

Store $0 \times 00$ in reg. B

Store $\mathrm{q}-1$ in reg. E

Store $0 \times 00$ in $\mathrm{reg}$. D

$\mathrm{H}-\mathrm{L}=0 \times 0000$

$\mathrm{H}-\mathrm{L}=\mathrm{H}-\mathrm{L}+\mathrm{B}-\mathrm{C}$

Indicates that current iteration is done

Is $\mathrm{D}-\mathrm{E}=0 \times 0000$ ?

If yes, go to LOOP27

Else, go to LOOP28

Store MSB of totient in address C40E

Store LSB of totient in address C40F

Store e in address C408

Store MSB of d-count

Store LSB of d-count

Reset Carry flag

$\mathrm{C}-\mathrm{D}-\mathrm{E}=0 \times 000000 \quad($ product $)$

Store e in reg. B

Store copy of MSB of $\mathrm{d}$-count in $\mathrm{C} 412$

Store copy of LSB of $d-$ count in C413

Add e to LSB of product

Add $0 \times 00$ to second byte of product with carry

Add $0 \times 00$ to MSB of product with carry

Store MSB of $\mathrm{d}$-count copy in $\mathrm{H}$

Store LSB of $d$-count copy in $L$

Decrement d-count copy

Is copy of $\mathrm{d}$-count $=0 \times 0000$ ?

If yes, go to LOOP29 
LABEL

\section{MNEMONICS}

MOV A, H

STA C412(H)

MOV A, L

STA C413(H)

JMP LOOP30

LOOP29

STC

CMC

LDA C40F (H)

MOV B, A

MOV A, E

SUB $B$

MOV E, A

LDA C40E (H)

MOV B, A

MOV A,D

SBB $B$

MOV D, A

MOV A, C

SBI $00(\mathrm{H})$

MOV C, A

MOV A, C

CPI $00(\mathrm{H})$

JNZ LOOP29

LDA C40E (H)

CMP D

JC LOOP29

LDA $\mathrm{C} 40 \mathrm{~F}(\mathrm{H})$

CMP E

JC LOOP29

JZ LOOP30

MOV A, E

CPI $01(\mathrm{H})$

JZ LOOP31

LOOP30 LDA C411(H)

ADI $01(\mathrm{H})$

STA $\mathrm{C} 411(\mathrm{H})$

LDA $\mathrm{C} 410(\mathrm{H})$

ACI $00(\mathrm{H})$

STA C410(H)

JMP LOOP32

LOOP31 LDA C410 (H)

STA $\mathrm{C} 406(\mathrm{H})$

LDA $\mathrm{C} 411(\mathrm{H})$

STA $\mathrm{C} 407(\mathrm{H})$

RET
COMMENTS

Else, load MSB of decremented d-count copy

to A

Store back in $\mathrm{C} 412(\mathrm{H})$

Load LSB of decremented d-count copy to A

Store back in $\mathrm{C} 413(\mathrm{H})$

And then, go to LOOP30

Reset Carry flag

Load LSB of totient to reg. B

Subtract LSB of totient from LSB of product

Update value of LSB of product

Load totient MSB to second product byte

Subtract totient MSB from second product byte Update value of second product byte

Subtract $0 \times 00$ from MSB of product with borrow Update value of MSB of product

Is MSB of product $0 \times 00$ ?

If not, go to LOOP29

Load MSB of totient to accumulator

Compare it with second product byte

If less, go to LOOP29

Else, load LSB of totient to accumulator

Compare it with LSB of product

If less, go to LOOP29

Else if, equal go to LOOP30

Else if not equal, do lines $88-90$

Compare LSB of product with $0 \times 01$

If equal, go to LOOP31

Else if not equal, do lines 91-97

Add $0 \times 01$ to LSB of $d-$ count

Update LSB of $d-$ count

Ad $0 \times 00$ to MSB of d-count with carry

Update MSB of d-count

And then, go to LOOP32

Store MSB of $d$-count in address C406

Store LSB of d-count in address C407

\section{Final implementation of encryption for transferring $1 \mathrm{kB}$ of data}

We now have all the sub-codes that are necessary to implement the transfer of multiple bytes of data with random pair of primes used for the encryption of every byte of data. In this section, we'll program the sender's multiprocessor to transfer a data of size $1 \mathrm{kB}$ to the receiver. To achieve this, codes in section 3.1, 4.2, and 4.3 needs to be applied in a cyclic form for each byte of data. For this all the 1000 message bytes needs to be stored as an array. We'll use memory locations FBE8 - FFCF for the same. Even the 1000 cipher texts (each of two bytes) that will be generated needs to be stored in a ciphertext array. We will utilize addresses F000 - F7CF for the same such that F000 and F001 contain the bytes of cipher text pertaining to first message byte, F002-F003 contains the second cipher text and so on. The flowchart for this implementation is given below: 


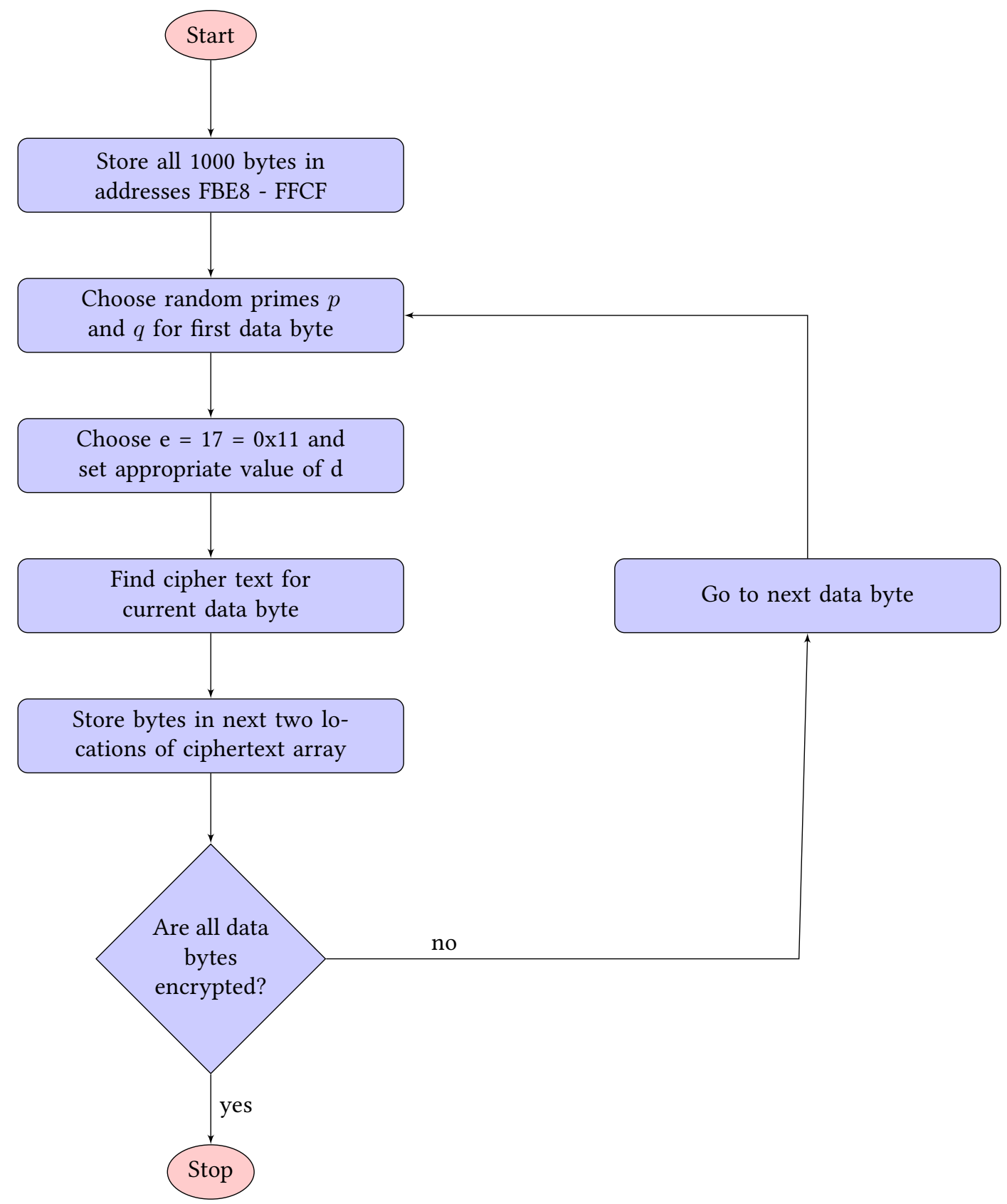

Figure 6: Final flowchart for transferring $1 \mathrm{kB}$ data

Parts of the codes in 3.1, 4.2 and 4.3 needs to be applied in a specific pattern cyclically. The following program is the final implementation that needs to be done on the microprocessor in the receiver's end for encrypting $1 \mathrm{kB}$ of data byte-wise. Before execution of the program, it is assumed that the concerned 1000 bytes of data are stored sequentially in address locations FBE8-FFC4 


\begin{tabular}{|c|c|c|c|c|}
\hline & LABEL & MNEMONICS & HEX CODE & COMMENTS \\
\hline D000 & CHOOSE & MVI A, $11(\mathrm{H})$ & $3 \mathrm{E}, 11$ & \\
\hline D002 & & STA FFD1 $(\mathrm{H})$ & $32, \mathrm{D} 1, \mathrm{FF}$ & Store $17=0 \times 11$ in address FFD 1 \\
\hline D005 & & MVI A, $13(\mathrm{H})$ & $3 \mathrm{E}, 13$ & \\
\hline D007 & & STA FFD2 $(\mathrm{H})$ & $32, \mathrm{D} 2, \mathrm{FF}$ & Store $19=0 \times 13$ in address FFD2 \\
\hline D00A & & MVI A, $17(\mathrm{H})$ & $3 \mathrm{E}, 17$ & \\
\hline D00C & & STA FFD3 $(\mathrm{H})$ & $32, \mathrm{D} 3, \mathrm{FF}$ & Store $23=0 \times 17$ in address FFD3 \\
\hline D00F & & MVI A, $1 \mathrm{D}(\mathrm{H})$ & $3 \mathrm{E}, 1 \mathrm{D}$ & \\
\hline D011 & & STA FFD4 $(\mathrm{H})$ & $32, \mathrm{D} 4, \mathrm{FF}$ & Store $29=0 \times 1 D$ in address FFD 4 \\
\hline D014 & & MVI A, $1 \mathrm{~F}(\mathrm{H})$ & $3 \mathrm{E}, 1 \mathrm{~F}$ & \\
\hline D016 & & STA FFD5 $(\mathrm{H})$ & $32, \mathrm{D} 5, \mathrm{FF}$ & Store $31=0 \times 1 \mathrm{~F}$ in address FFD5 \\
\hline D019 & & MVI A,25(H) & $3 \mathrm{E}, 25$ & \\
\hline D01B & & STA FFD6 $(\mathrm{H})$ & $32, \mathrm{D} 6, \mathrm{FF}$ & Store $37=0 \times 25$ in address FFD6 \\
\hline D01E & & MVI A,29(H) & $3 \mathrm{E}, 29$ & \\
\hline D020 & & STA FFD7 $(\mathrm{H})$ & $32, \mathrm{D} 7, \mathrm{FF}$ & Store $41=0 \times 29$ in address FFD7 \\
\hline D023 & & MVI A,2 B (H) & $3 \mathrm{E}, 2 \mathrm{~B}$ & \\
\hline D025 & & STA FFD $8(\mathrm{H})$ & $32, \mathrm{D} 8, \mathrm{FF}$ & Store $43=0 \times 2 B$ in address FFD 8 \\
\hline D028 & & MVI A, $2 \mathrm{~F}(\mathrm{H})$ & $3 \mathrm{E}, 2 \mathrm{~F}$ & \\
\hline D02A & & STA FFD9 $(\mathrm{H})$ & $32, \mathrm{D} 9, \mathrm{FF}$ & Store $47=0 \times 2 \mathrm{~F}$ in address FFD9 \\
\hline D02D & & MVI A, $35(\mathrm{H})$ & $3 \mathrm{E}, 35$ & \\
\hline $\mathrm{D} 02 \mathrm{~F}$ & & STA FFDA $(\mathrm{H})$ & $32, \mathrm{DA}, \mathrm{FF}$ & Store $53=0 \times 35$ in address FFDA \\
\hline D032 & & MVI A, $3 \mathrm{~B}(\mathrm{H})$ & $3 \mathrm{E}, 3 \mathrm{~B}$ & \\
\hline D034 & & STA FFDB $(\mathrm{H})$ & $32, \mathrm{DB}, \mathrm{FF}$ & Store $59=0 \times 3 B$ in address FFDB \\
\hline D037 & & MVI A, 3D(H) & $3 \mathrm{E}, 3 \mathrm{D}$ & \\
\hline D039 & & STA FFDC $(\mathrm{H})$ & $32, \mathrm{DC}, \mathrm{FF}$ & Store $61=0 \times 3 D$ in address FFDC \\
\hline D03C & & MVI A, $43(\mathrm{H})$ & $3 \mathrm{E}, 43$ & \\
\hline D03E & & STA FFDD $(\mathrm{H})$ & $32, \mathrm{DD}, \mathrm{FF}$ & Store $67=0 \times 43$ in address FFDD \\
\hline D041 & & CALL STARTRAND & $\mathrm{CD}, 62, \mathrm{D} 2$ & Call STARTRAND function \\
\hline D044 & & MVI A, FB (H) & $3 \mathrm{E}, \mathrm{FB}$ & \\
\hline D046 & & STA C414(H) & $32,14, \mathrm{C} 4$ & Store MSB of 1 st message byte address in C 414 \\
\hline D049 & & MVI A, E8 (H) & $3 \mathrm{E}, \mathrm{E} 8$ & \\
\hline D04B & & STA C $415(\mathrm{H})$ & $32,15, \mathrm{C} 4$ & Store LSB of 1 st message byte address in C 415 \\
\hline D04E & & MVI A, F0 (H) & $3 \mathrm{E}, \mathrm{F} 0$ & \\
\hline & & STA C416(H) & & Store MSB of pointer to ciphertext array in \\
\hline D050 & & & $32,16, \mathrm{C} 4$ & $\mathrm{C} 416$ \\
\hline D053 & & MVI A, $00(\mathrm{H})$ & $3 \mathrm{E}, 00$ & \\
\hline D055 & & STA $\mathrm{C} 417(\mathrm{H})$ & $32,17, \mathrm{C} 4$ & $\begin{array}{l}\text { Store LSB of pointer to ciphertext array in } \\
\text { C } 417\end{array}$ \\
\hline D058 & START & LDA C414(H) & $3 \mathrm{~A}, 14, \mathrm{C} 4$ & \\
\hline D05B & & MOV D, A & 57 & \\
\hline D05C & & LDA C $415(\mathrm{H})$ & $3 \mathrm{~A}, 15, \mathrm{C} 4$ & \\
\hline $\mathrm{D} 05 \mathrm{~F}$ & & MOV E, A & $5 \mathrm{~F}$ & $\mathrm{D}-\mathrm{E}=$ first message byte \\
\hline D060 & & LDAX D & $1 \mathrm{~A}$ & \\
\hline D061 & & STA C $407(\mathrm{H})$ & $32,07, \mathrm{C} 4$ & Store current message byte in address $\mathrm{C} 407$ \\
\hline D064 & & MVI A, $11(\mathrm{H})$ & $3 \mathrm{E}, 11$ & \\
\hline D066 & & STA C $408(\mathrm{H})$ & $32,08, \mathrm{C} 4$ & Store e in address C408 \\
\hline D069 & & MVI A, $11(\mathrm{H})$ & $3 \mathrm{E}, 11$ & \\
\hline D06B & & STA C $409(\mathrm{H})$ & $32,09, \mathrm{C} 4$ & Store max. byte size in address C409 \\
\hline D06E & & CALL ANOTHER & $\mathrm{CD}, 0 \mathrm{D}, \mathrm{D} 3$ & Call function ANOTHER \\
\hline D071 & & LDA C3F3 $(\mathrm{H})$ & $3 \mathrm{~A}, \mathrm{~F} 3, \mathrm{C} 3$ & Load the random no. generated \\
\hline D074 & & ADI $01(\mathrm{H})$ & C6, 01 & Add $0 \times 01$ to this random no. \\
\hline D076 & & MOV C, A & $4 \mathrm{~F}$ & And store it in reg. C \\
\hline D077 & & LXI H FFD0 $(\mathrm{H})$ & $21, \mathrm{D} 0, \mathrm{FF}$ & $\begin{array}{l}\text { Load address preceding that of first prime } \\
\text { in HL reg. pair }\end{array}$ \\
\hline D07A & & INX H & 23 & Go to next prime \\
\hline D07B & NEXTPRIME & DCR C & $0 \mathrm{D}$ & Have we reached the required index? \\
\hline D07C & & JNZ NEXTPRIME & $\mathrm{C} 2,7 \mathrm{~B}, \mathrm{D} 0$ & If not, go to NEXTPRIME \\
\hline D07F & & MOV A,M & $7 \mathrm{E}$ & Else load current prime no. to accumulator \\
\hline D080 & & STA C40C $(\mathrm{H})$ & $32,0 \mathrm{C}, \mathrm{C} 4$ & And store it in $\mathrm{C} 40 \mathrm{C}$ (this is p) \\
\hline
\end{tabular}


LABEL

D083

D086

D089

D08B

D08C

D08F

D090

D091

D094

D095

D098

D09B

D09C

D09E

D101

D104

D105

D106

D107

D10A

D10B

D10E

D10F

D112

D115

D116

D119

D11B

D11C

D11D

D120

D121

D124

D125

D126

D129

D12A

D12D

D12E

D131

D134

D135

D136

D137

D13A

D13B

D13C

D13F

D142

D143

D146

D147

D14A

D14D

D14E

NXT

LOOP1

LOOP2

DONE

LOOP4

\section{MNEMONICS}

CALL ANOTHER

LDA C3F3 $(\mathrm{H})$

ADI $01(\mathrm{H})$

MOV C, A

LXI H FFD0 $(\mathrm{H})$

INX $\mathrm{H}$

DCR C

JNZ NEXTPRIME

MOV A,M

STA C40D (H)

LDA $\mathrm{C} 40 \mathrm{C}(\mathrm{H})$

MOV E, A

MVI D, $00(\mathrm{H})$

LXI H, $0000(\mathrm{H})$

LDA C40D $(\mathrm{H})$

MOV B, A

DAD D

DCR B

JNZ NXT

MOV A, H

STA C40A (H)

MOV A, L

STA $\mathrm{C} 40 \mathrm{~B}(\mathrm{H})$

LDA C408 (H)

MOV E, A

LXI H FFEF $(\mathrm{H})$

MVI A, $00(\mathrm{H})$

MOV M, A

DCR E

JZ LOOP2

INX $\mathrm{H}$

JMP LOOP1

STC

CMC

LDA C408(H)

MOV E, A

LDA C409(H)

MOV B, A

REPEAT1

REPEAT

LXI H FFDE $(\mathrm{H})$

LXI D $\operatorname{FFEF}(\mathrm{H})$

LDAX D

MOV M, A

DCR B

JZ DONE

INX $\mathrm{H}$

INX D

JMP REPEAT
HEX CODE

$\mathrm{CD}, 0 \mathrm{D}, \mathrm{D} 3$

$3 \mathrm{~A}, \mathrm{~F} 3, \mathrm{C} 3$

C6, 01

$4 \mathrm{~F}$

$21, \mathrm{D} 0, \mathrm{FF}$

23

$0 \mathrm{D}$

C2, 7 B, D0

$7 \mathrm{E}$

$32,0 \mathrm{D}, \mathrm{C} 4$

$3 \mathrm{~A}, 0 \mathrm{C}, \mathrm{C} 4$

$5 \mathrm{~F}$

16,00

$21,00,00$

$3 \mathrm{~A}, 0 \mathrm{D}, \mathrm{C} 4$

47

19

05

$\mathrm{C} 2,05, \mathrm{D} 1$

$7 \mathrm{C}$

$32,0 \mathrm{~A}, \mathrm{C} 4$

$7 \mathrm{D}$

$32,0 \mathrm{~B}, \mathrm{C} 4$

$3 \mathrm{~A}, 08, \mathrm{C} 4$

$5 \mathrm{~F}$

$21, \mathrm{EF}, \mathrm{FF}$

$3 \mathrm{E}, 00$

77

$1 \mathrm{D}$

CA, 24 , D1

23

C3, 19, D1

37

$3 \mathrm{~F}$

$3 \mathrm{~A}, 08, \mathrm{C} 4$

$5 \mathrm{~F}$

$3 \mathrm{~A}, 09, \mathrm{C} 4$

47

21 , DE, FF

$11, \mathrm{EF}, \mathrm{FF}$

$1 \mathrm{~A}$

77

05

CA, 3 F , D1

23

13

$\mathrm{C} 3,34, \mathrm{D} 1$

$3 \mathrm{~A}, 07, \mathrm{C} 4$

$4 \mathrm{~F}$

$3 \mathrm{~A}, 09, \mathrm{C} 4$

47

$21, \mathrm{FF}, \mathrm{FF}$

$11, \mathrm{EE}, \mathrm{FF}$

37

$3 \mathrm{~F}$
COMMENTS

Go to embedded function ANOTHER

Do the same steps as done for $p$ for $q$

Store $q$ in address C40D

Store $p$ in reg. E

Initialize reg. $D=0 \times 00$

Set contents of HL reg. pair to $0 \times 0000$

Load q to reg. B

Add DE reg. pair to HL reg. pair

If NXT has not been executed q times repeat NXT

Store higher order byte of $n$ in address C40A

Store lower order byte of $n$ in address $C 40 B$

Move e to reg. E

Initialize reg. pair HL with address of MSB

Initialize data at memory location to $0 \times 00$

If all 17 address locations are initialized to $0 \times 00$, go to LOOP2

If all 17 address location are not initialized point memory next address byte \& go to LOOP1

Reset Carry flag

Load e to reg. E

Store max byte size in reg. B

$H-L$ points to content at address FFDE

D-E points to MSB which will converge to c

Copy content of DE reg, pair to memory

Check if all 17 bytes are copied

If yes, go to DONE

Else, increment contents of HL reg. pair

And increment contents of DE reg. pair

An then go to REPEAT

Store $m$ in reg. C

Store max byte size in reg. B

Memory points to actual LSB

DE reg. pair points to copy LSB

Reset carry flag 


\begin{tabular}{|c|c|c|c|c|}
\hline & LABEL & MNEMONICS & HEX CODE & COMMENTS \\
\hline $\mathrm{D} 14 \mathrm{~F}$ & LOOP5 & LDAX D & $1 \mathrm{~A}$ & \\
\hline D150 & & ADC M & $8 \mathrm{E}$ & \\
\hline D151 & & MOV M, A & 77 & Add copy LSB to actual LSB \\
\hline D152 & & DCR B & 05 & Indicates that current byte is updated \\
\hline D153 & & JZ NEXT & $\mathrm{CA}, 5 \mathrm{~B}, \mathrm{D} 1$ & If all bytes are updated go to NEXT \\
\hline D156 & & DCX H & $2 \mathrm{~B}$ & Else, point memory to next LSB \\
\hline D157 & & DCX D & $1 \mathrm{~B}$ & Point DE reg. pair to next LSB of copy \\
\hline D158 & & JMP LOOP5 & $\mathrm{C} 3,4 \mathrm{~F}, \mathrm{D} 1$ & And go to LOOP5 \\
\hline D15B & NEXT & DCR C & $0 \mathrm{D}$ & Indicates that current iteration is done \\
\hline D15C & & JZ LOOP3 & $\mathrm{CA}, 62, \mathrm{D} 1$ & If all $\mathrm{m}$ iterations are done, go to LOOP3 \\
\hline D15F & & JMP LOOP4 & $\mathrm{C} 3,43, \mathrm{D} 1$ & If not, go to LOOP4 \\
\hline D162 & LOOP3 & DCR E & $1 \mathrm{D}$ & Indicates that current iteration is done \\
\hline D163 & & JZ LOOP8 & $\mathrm{CA}, 69$, D1 & If all e iterations are completed go to LOOP8 \\
\hline D166 & & JMP REPEAT1 & $\mathrm{C} 3,2 \mathrm{E}, \mathrm{D} 1$ & Else, go to REPEAT1 \\
\hline D169 & LOOP8 & STC & 37 & \\
\hline D16A & & CMC & $3 \mathrm{~F}$ & Reset Carry flag \\
\hline D16B & & LDA C $409(\mathrm{H})$ & $3 \mathrm{~A}, 09, \mathrm{C} 4$ & \\
\hline D16E & & MOV B, A & 47 & Load max byte no. to reg. B \\
\hline D16F & & LDA $\mathrm{C} 40 \mathrm{~A}(\mathrm{H})$ & $3 \mathrm{~A}, 0 \mathrm{~A}, \mathrm{C} 4$ & \\
\hline D172 & & MOV D, A & 57 & Load higher order bit of $n$ to reg. D \\
\hline D173 & & LDA $\mathrm{C} 40 \mathrm{~B}(\mathrm{H})$ & $3 \mathrm{~A}, 0 \mathrm{~B}, \mathrm{C} 4$ & \\
\hline D176 & & MOV E, A & $5 \mathrm{~F}$ & Load lower order bit of $n$ to reg. E \\
\hline D177 & & LXI H, FFFF $(\mathrm{H})$ & $21, \mathrm{FF}, \mathrm{FF}$ & Initialize reg. pair HL with address of LSB \\
\hline D17A & & MOV A,M & $7 \mathrm{E}$ & \\
\hline D17B & & SUB E & 93 & Subtract lower order bit of $n$ from LSB \\
\hline D17C & & MOV M, A & 77 & Update value of LSB \\
\hline D17D & & DCR B & 05 & Indicates that LSB is updated \\
\hline D17E & & DCX H & $2 \mathrm{~B}$ & Point memory to next LSB \\
\hline D17F & & MOV A,M & $7 \mathrm{E}$ & \\
\hline D180 & & SBB D & $9 \mathrm{~A}$ & $\begin{array}{l}\text { Subtract higher order bit of } n \text { from second } \\
\text { LSB with borrow }\end{array}$ \\
\hline D181 & & MOV M, A & 77 & Update value of second LSB \\
\hline D182 & & DCR B & 05 & Indicates that second LSB is updated \\
\hline D183 & LOOP6 & DCX H & $2 \mathrm{~B}$ & Point memory to next LSB \\
\hline D184 & & MOV A,M & $7 \mathrm{E}$ & \\
\hline D185 & & SBI $\quad 00(\mathrm{H})$ & DF, 00 & Subtract $0 \times 00$ from current byte with borrow \\
\hline D187 & & MOV M, A & 77 & Update value of current byte \\
\hline D188 & & DCR B & 05 & Indicates that current byte has been updated \\
\hline D189 & & JZ LOOP7 & $\mathrm{CA}, 8 \mathrm{~F}, \mathrm{D} 1$ & $\begin{array}{l}\text { If all bytes of current iteration are updated } \\
\text { go to LOOP7 }\end{array}$ \\
\hline D18C & & JMP LOOP6 & $\mathrm{C} 3,83, \mathrm{D} 1$ & $\begin{array}{l}\text { If all bytes of current iteration are not } \\
\text { updated, go to LOOP6 }\end{array}$ \\
\hline D18F & LOOP7 & LDA $\mathrm{C} 409(\mathrm{H})$ & $3 \mathrm{~A}, 09, \mathrm{C} 4$ & \\
\hline D192 & & SUI $02(\mathrm{H})$ & D6, 02 & Subtract $0 \times 02$ from $\max$ bit size \\
\hline D194 & & MOV B, A & 47 & Store max bit size -2 in $r e g . B$ \\
\hline D195 & & LXI H FFEF $(\mathrm{H})$ & $21, \mathrm{EF}, \mathrm{FF}$ & Load memory with address of MSB \\
\hline D198 & LOOP9 & MOV A,M & $7 \mathrm{E}$ & \\
\hline D199 & & CPI $00(\mathrm{H})$ & $\mathrm{FE}, 00$ & Compare current byte with $0 \times 00$ \\
\hline D19B & & JNZ LOOP8 & $\mathrm{C} 2,69, \mathrm{D} 1$ & If current byte is not $0 \times 00$, go to LOOP 8 \\
\hline D19E & & DCR B & 05 & $\begin{array}{l}\text { Indicates that current byte has been found to } \\
\text { be } 0 \times 00\end{array}$ \\
\hline D19F & & JZ LOOP10 & $\mathrm{CA}, 05, \mathrm{D} 2$ & $\begin{array}{l}\text { If first } 15 \text { bytes have been compared go to } \\
\text { LOOP } 10\end{array}$ \\
\hline D202 & & INX H & 23 & $\begin{array}{l}\text { If first } 15 \text { bytes have not yet been compared } \\
\text { point memory to next MSB }\end{array}$ \\
\hline D203 & & JMP LOOP9 & $\mathrm{C} 3,98, \mathrm{D} 1$ & \\
\hline D205 & LOOP10 & INX H & 23 & \\
\hline D206 & & MOV A,D & $7 \mathrm{~A}$ & \\
\hline
\end{tabular}


LABEL

D207

D208

D20B

D20E

D211

D212

D213

D214

D217

D21A

D21C

D21F

D221

D224

D227

D228

D22B

D22C

D22F

D230

D231

D234

D235

D236

D237

D23A

D23B

D23E

D241

D242

D245

D246

D247

D248

D24A

D24D

D24E

D251

D252

D255

D258

D259

D25B

D25E

D261

AGAIN

STOP
MNEMONICS

CMP M

JZ LOOP11

JC LOOP8

JMP LOOP12

INX H

MOV A, E

CMP M

JC LOOP8

JNZ LOOP12

MVI A, $00(\mathrm{H})$

STA FFFE $(\mathrm{H})$

MVI A, $00(\mathrm{H})$

STA FFFF (H)

LOOP12

LDA C416(H)

MOV D, A

LDA $\mathrm{C} 417(\mathrm{H})$

MOV E, A

LDA FFFE $(\mathrm{H})$

STAX D

INX D

LDA FFFF $(\mathrm{H})$

STAX D

INX D

MOV A,D

STA C416(H)

MOV A, E

STA $\mathrm{C} 417(\mathrm{H})$

LDA $\mathrm{C} 414(\mathrm{H})$

MOV D, A

LDA C415(H)

MOV E, A

INX D

MOV A,D

CPI FF (H)

JZ CHECK2

MOV A,D

STA C414 $(\mathrm{H})$

MOV A, E

STA C415(H)

JMP START

MOV A, E

CPI D0 $(\mathrm{H})$

JZ STOP

JMP AGAIN
HEX CODE

$\mathrm{BE}$

CA, 11 , D2

DA, 69 , D1

C3, 24, D2

23

$7 \mathrm{~B}$

BE

DA, 69 , D1

$\mathrm{C} 2,24, \mathrm{D} 2$

$3 \mathrm{E}, 00$

$32, \mathrm{FE}, \mathrm{FF}$

$3 \mathrm{E}, 00$

$32, \mathrm{FF}, \mathrm{FF}$

$3 \mathrm{~A}, 16, \mathrm{C} 4$

57

$3 \mathrm{~A}, 17, \mathrm{C} 4$

$5 \mathrm{~F}$

$21, \mathrm{FE}, \mathrm{FF}$

12

13

21, FFFF

12

13

$7 \mathrm{~A}$

$32,16, \mathrm{C} 4$

$7 \mathrm{~B}$

$32,17, \mathrm{C} 4$

$3 \mathrm{~A}, 14, \mathrm{C} 4$

57

$3 \mathrm{~A}, 15, \mathrm{C} 4$

$5 \mathrm{~F}$

13

$7 \mathrm{~A}$

$\mathrm{FE}, \mathrm{FF}$

CA, 58 , D2

$7 \mathrm{~A}$

$32,14, \mathrm{C} 4$

$7 \mathrm{~B}$

$32,15, \mathrm{C} 4$

$\mathrm{C} 3,58, \mathrm{D} 0$

78

FE , D0

CA, 61 , D2

C3 , 4 D, D2

76
COMMENTS

Compare higher order bits of $n$ with data at address FFFE

If they are equal, go to LOOP 11

If they are not equal and address at FFFE is greater than higher order bits of $n$, go to LOOP8

Else if they are equal and address at FFFE is

less than higher byte of $\mathrm{n}$, go to LOOP 12

Compare lower order bits of $\mathrm{n}$ with data at address FFFF

If address at FFFF is less than the lower order bits of $n$, go to LOOP8

Else if they are not equal, go to LOOP12

Else if they are equal, proceed

Set value at address $F F F E=0 \times 00$

Set value at address FFFF $=0 \times 00$

Load MSB of ciphertext array pointer address to reg. D

Load LSB of ciphertext array pointer address to reg. E

Load MSB of ciphertext generated to A

And store in ciphertext array pointer

Increment pointer to point to next address

Load LSB of ciphertext generated to A

And store in ciphertext array pointer

Increment pointer to point to next address

Store MSB of incremented pointer back to C416

Store LSB of incremented pointer back to C417

$D-E$ = pointer of message byte array

Current byte has been encrypted

Check if MSB of incremented pointer $=\mathrm{FF}$

If yes, go to CHECK2

Else, proceed

Store MSB of incremented pointer back to C414

Store LSB of incremented pointer bacl to C415

And then, go to START

Check if LSB of incremented pointer = D0

If yes, terminate the program

Else, go to AGAIN 


\begin{tabular}{|c|c|c|c|c|}
\hline & LABEL & MNEMONICS & HEX CODE & COMMENTS \\
\hline D262 & STARTRAND & MVI A, $19(\mathrm{H})$ & $3 \mathrm{E}, 19$ & \\
\hline D264 & & STA C $400(\mathrm{H})$ & $32,00, \mathrm{C} 4$ & Store MSB of A \\
\hline D267 & & MVI A, $66(\mathrm{H})$ & $3 \mathrm{E}, 66$ & \\
\hline D269 & & STA C $401(\mathrm{H})$ & $32,01, \mathrm{C} 4$ & Store second byte of A \\
\hline D26C & & MVI A,0D(H) & $3 \mathrm{E}, 0 \mathrm{D}$ & \\
\hline D26E & & STA C $402(\mathrm{H})$ & $32,02, \mathrm{C} 4$ & Store LSB of A \\
\hline D271 & & MVI A, $3 \mathrm{C}(\mathrm{H})$ & $3 \mathrm{E}, 3 \mathrm{C}$ & \\
\hline D273 & & STA C $3 F C(H)$ & $32, \mathrm{FC}, \mathrm{C} 3$ & Store MSB of C \\
\hline D276 & & MVI A, $6 \mathrm{E}(\mathrm{H})$ & $3 \mathrm{E}, 6 \mathrm{E}$ & \\
\hline D278 & & STA C3FD $(\mathrm{H})$ & $32, \mathrm{FD}, \mathrm{C} 3$ & Store second MSB of C \\
\hline D27B & & MVI A, F3 (H) & $3 \mathrm{E}, \mathrm{F} 3$ & \\
\hline D27D & & STA C3FE $(\mathrm{H})$ & $32, \mathrm{FE}, \mathrm{C} 3$ & Store second LSB of C \\
\hline D280 & & MVI A, $5 \mathrm{~F}(\mathrm{H})$ & $3 \mathrm{E}, 5 \mathrm{~F}$ & \\
\hline D282 & & STA C C FF $(\mathrm{H})$ & $32, \mathrm{FF}, \mathrm{C} 3$ & Store LSB of C \\
\hline D285 & & MVI C, $08(\mathrm{H})$ & $0 \mathrm{E}, 08$ & \\
\hline D287 & & LXI H C3F4 (H) & $21, \mathrm{~F} 4, \mathrm{C} 3$ & \\
\hline D28A & SET1 & MVI A, $00(\mathrm{H})$ & $3 \mathrm{E}, 00$ & \\
\hline D28C & & MOV M, A & 77 & \\
\hline D28D & & DCR C & $0 \mathrm{D}$ & \\
\hline D28E & & JZ SET2 & $\mathrm{CA}, 95, \mathrm{D} 2$ & \\
\hline D291 & & INX H & 23 & \\
\hline D292 & & JMP SET 1 & $\mathrm{C} 3,8 \mathrm{~A}, \mathrm{D} 2$ & Set initial seed $=0 \times 00000000$ \\
\hline D295 & SET2 & LDA $\mathrm{C} 3 \mathrm{~F} 8(\mathrm{H})$ & $3 \mathrm{~A}, \mathrm{~F} 8, \mathrm{C} 3$ & \\
\hline D298 & & STA C403(H) & $32,03, \mathrm{C} 4$ & Copy 5 th byte of seed \\
\hline D29B & & LDA C3F9 $(\mathrm{H})$ & $3 \mathrm{~A}, \mathrm{~F} 9, \mathrm{C} 3$ & \\
\hline D29E & & STA C $404(\mathrm{H})$ & $32,04, \mathrm{C} 4$ & Copy 6 th byte of seed \\
\hline D301 & & LDA C3FA $(\mathrm{H})$ & $3 \mathrm{~A}, \mathrm{FA}, \mathrm{C} 3$ & \\
\hline D304 & & STA C $405(\mathrm{H})$ & $32,05, \mathrm{C} 4$ & Copy 7 th byte of seed \\
\hline D307 & & LDA C3FB $(\mathrm{H})$ & $3 \mathrm{~A}, \mathrm{FB}, \mathrm{C} 3$ & \\
\hline D30A & & STA C406(H) & $32,06, \mathrm{C} 4$ & Copy 8 th byte (LSB) of seed \\
\hline D30D & ANOTHER & LDA C $400(\mathrm{H})$ & $3 \mathrm{~A}, 00, \mathrm{C} 4$ & \\
\hline D310 & & MOV C, A & $4 \mathrm{~F}$ & Store MSB of $A$ in reg. C \\
\hline D311 & & LDA C $401(\mathrm{H})$ & $3 \mathrm{~A}, 01, \mathrm{C} 4$ & \\
\hline D314 & & MOV D, A & 57 & Store second byte of $A$ in reg. D \\
\hline D315 & & LDA C $402(\mathrm{H})$ & $3 \mathrm{~A}, 02, \mathrm{C} 4$ & \\
\hline D318 & & MOV E, A & $5 \mathrm{~F}$ & Store LSB of $A$ in reg. $E$ \\
\hline D319 & LOOP14 & LXI H C3FB (H) & $21, \mathrm{FB}, \mathrm{C} 3$ & Point memory to LSB of seed \\
\hline D31C & & LDA C $406(\mathrm{H})$ & $3 \mathrm{~A}, 06, \mathrm{C} 4$ & \\
\hline D31F & & ADD $M$ & 86 & Add LSB of initial seed to current memory \\
\hline D320 & & MOV M, A & 77 & Update value of current byte \\
\hline D321 & & DCX H & $2 \mathrm{~B}$ & Point memory to second LSB of seed \\
\hline D322 & & LDA C $405(\mathrm{H})$ & $3 \mathrm{~A}, 05, \mathrm{C} 4$ & \\
\hline D325 & & $\mathrm{ADC} M$ & $8 \mathrm{E}$ & $\begin{array}{l}\text { Add second LSB of initial seed to memory with } \\
\text { carry }\end{array}$ \\
\hline D326 & & MOV M, A & 77 & Update value of current byte \\
\hline D327 & & DCX H & $2 \mathrm{~B}$ & Point memory to third LSB of seed \\
\hline D328 & & LDA C $404(\mathrm{H})$ & $3 \mathrm{~A}, 04, \mathrm{C} 4$ & \\
\hline D32B & & ADC $M$ & $8 \mathrm{E}$ & $\begin{array}{l}\text { Add third LSB of initial seed to memory with } \\
\text { carry }\end{array}$ \\
\hline D32C & & MOV M, A & 77 & Update value of current byte \\
\hline D32D & & DCX H & $2 \mathrm{~B}$ & Point memory to fourth LSB of seed \\
\hline D32E & & LDA C $403(\mathrm{H})$ & $3 \mathrm{~A}, 03, \mathrm{C} 4$ & \\
\hline D331 & & ADC $M$ & $8 \mathrm{E}$ & $\begin{array}{l}\text { Add fourth LSB of initial seed to memory with } \\
\text { carry }\end{array}$ \\
\hline D332 & & MOV M, A & 77 & Update value of current byte \\
\hline D333 & & DCX H & $2 \mathrm{~B}$ & Point memory to next LSB of seed \\
\hline D334 & & MVI B,04(H) & 06,04 & Initialize reg. B to $04(\mathrm{H})$ \\
\hline
\end{tabular}




\begin{tabular}{|c|c|c|c|c|}
\hline & LABEL & MNEMONICS & HEX CODE & COMMENTS \\
\hline D336 & LOOP26 & MOV A,M & $7 \mathrm{E}$ & \\
\hline D337 & & ACI $00(\mathrm{H})$ & $\mathrm{CF}, 00$ & Add $0 \times 00$ to current seed byte with carry \\
\hline D339 & & MOV M, A & 77 & Update value of current byte \\
\hline D33A & & DCR B & 05 & Indicates that current byte has been updated \\
\hline D33B & & JZ LOOP25 & $\mathrm{CA}, 42$, D3 & If all bytes of seed are updated, go to LOOP2 \\
\hline D33E & & DCX H & $2 \mathrm{~B}$ & Else, point memory to next LSB of seed \\
\hline D33F & & JMP LOOP26 & $\mathrm{C} 3,36, \mathrm{D} 3$ & And then go to LOOP 26 \\
\hline D342 & LOOP25 & MOV A, E & $7 \mathrm{~B}$ & \\
\hline D343 & & SUI $01(\mathrm{H})$ & D6, 01 & \\
\hline D345 & & MOV E, A & $5 \mathrm{~F}$ & Subtract $0 \times 01$ from reg. E \\
\hline D346 & & MOV A,D & $7 \mathrm{~A}$ & \\
\hline D347 & & SBI $00(\mathrm{H})$ & DF, 00 & \\
\hline D349 & & MOV D, A & 57 & Subtract $0 \times 00$ from reg. D with borrow \\
\hline D34A & & MOV A,C & 79 & \\
\hline D34B & & SBI $00(\mathrm{H})$ & DF, 00 & \\
\hline D34D & & MOV C,A & $4 \mathrm{~F}$ & Subtract $0 \times 00$ from reg. C with borrow \\
\hline D34E & & MOV A, C & 79 & \\
\hline D34F & & ORA D & B2 & Is reg. $C=$ reg. $D=0 \times 00 ?$ \\
\hline D350 & & JZ LOOP13 & $\mathrm{CA}, 56, \mathrm{D} 3$ & If yes, go to LOOP13 \\
\hline D353 & & JMP LOOP14 & $\mathrm{C} 3,19, \mathrm{D} 3$ & If not, go to LOOP 14 \\
\hline D356 & LOOP13 & MOV A,E & 7B & \\
\hline D357 & & CPI $00(\mathrm{H})$ & $\mathrm{FE}, 00$ & Is reg.E $=0 \times 00 ?$ \\
\hline D359 & & JZ LOOP15 & $\mathrm{CA}, 5 \mathrm{~F}, \mathrm{D} 3$ & If yes, go to LOOP 15 \\
\hline $\mathrm{D} 35 \mathrm{C}$ & & JMP LOOP14 & $\mathrm{C} 3,19, \mathrm{D} 3$ & If not, go to LOOP14 \\
\hline D35F & LOOP15 & LXI H, C3FB $(\mathrm{H})$ & $21, \mathrm{FB}, \mathrm{C} 3$ & Point memory to LSB of seed \\
\hline D362 & & LDA $\mathrm{C} 3 \mathrm{FF}(\mathrm{H})$ & $3 \mathrm{~A}, \mathrm{FF}, \mathrm{C} 3$ & \\
\hline D365 & & ADD M & 86 & \\
\hline D366 & & MOV M, A & 77 & Add LSB of $C$ to LSB of seed \\
\hline D367 & & DCX H & $2 \mathrm{~B}$ & Point memory to second LSB of seed \\
\hline D368 & & LDA C3FE $(\mathrm{H})$ & $3 \mathrm{~A}, \mathrm{FE}, \mathrm{C} 3$ & \\
\hline D36B & & ADC M & $8 \mathrm{E}$ & \\
\hline D36C & & MOV M, A & 77 & $\begin{array}{l}\text { Add second LSB of C to second LSB of seed } \\
\text { with carry }\end{array}$ \\
\hline D36D & & DCX H & $2 \mathrm{~B}$ & Point memory to third LSB of seed \\
\hline D36E & & LDA C3FD & $3 \mathrm{~A}, \mathrm{FD}, \mathrm{C} 3$ & \\
\hline D371 & & ADC M & $8 \mathrm{E}$ & \\
\hline D372 & & MOV M, A & 77 & $\begin{array}{l}\text { Add second LSB of C to second LSB of seed } \\
\text { with carry }\end{array}$ \\
\hline D373 & & DCX H & oB & Point memory to third LSB of seed \\
\hline D374 & & LDA C3FC & $3 \mathrm{~A}, \mathrm{FC}, \mathrm{C} 3$ & \\
\hline D377 & & ADC M & $8 \mathrm{E}$ & \\
\hline D378 & & MOV M, A & 77 & $\begin{array}{l}\text { Add second LSB of C to third LSB of seed } \\
\text { with carry }\end{array}$ \\
\hline D379 & & DCX H & $0 \mathrm{~B}$ & Point memory to third fourth of seed \\
\hline D37A & & MVI $\mathrm{B}, \quad 04(\mathrm{H})$ & 06,04 & Set reg. $B=0 \times 04$ \\
\hline D37C & LOOP17 & ACI $00(\mathrm{H})$ & $\mathrm{CF}, 00$ & \\
\hline D37E & & MOV M, A & 77 & Add $0 \times 00$ to current byte of seed \\
\hline D37F & & DCR B & 05 & Indicates that current seed byte is updated \\
\hline D380 & & JZ LOOP16 & $\mathrm{CA}, 87, \mathrm{D} 3$ & If all seed bytes are updated go to LOOP16 \\
\hline D383 & & DCX H & $2 \mathrm{~B}$ & If not, point memory to next LSB of seed \\
\hline D384 & & JMP LOOP17 & $\mathrm{C} 3,7 \mathrm{C}, \mathrm{D} 3$ & And then go to LOOP17 \\
\hline D387 & LOOP16 & LDA C3F8 $(\mathrm{H})$ & $3 \mathrm{~A}, \mathrm{~F} 8, \mathrm{C} 3$ & \\
\hline D38A & & STA $\mathrm{C} 403(\mathrm{H})$ & $32,03, \mathrm{C} 4$ & Store MSB of seed in address $\mathrm{C} 403$ \\
\hline D38D & & LDA C3F9 $(\mathrm{H})$ & $3 \mathrm{~A}, \mathrm{~F} 9, \mathrm{C} 3$ & \\
\hline D390 & & STA $\mathrm{C} 404(\mathrm{H})$ & $32,04, \mathrm{C} 4$ & Store second MSB of seed in address C 404 \\
\hline D393 & & LDA C3FA $(\mathrm{H})$ & $3 \mathrm{~A}, \mathrm{FA}, \mathrm{C} 3$ & \\
\hline D396 & & STA $\mathrm{C} 405(\mathrm{H})$ & $32,05, \mathrm{C} 4$ & Store second LSB of seed in address C405 \\
\hline D399 & & LDA C3FB $(\mathrm{H})$ & $3 \mathrm{~A}, \mathrm{FB}, \mathrm{C} 3$ & \\
\hline
\end{tabular}




\begin{tabular}{|c|c|c|c|c|}
\hline & LABEL & MNEMONICS & HEX CODE & COMMENTS \\
\hline D39C & & STA $\mathrm{C} 406(\mathrm{H})$ & $32,06, \mathrm{C} 4$ & Store LSB of seed in address C406 \\
\hline D39F & & MVI $\mathrm{B}, 0 \mathrm{D}(\mathrm{H})$ & $06,0 \mathrm{D}$ & Store $13=0 \mathrm{x} 0 \mathrm{D}$ in $\mathrm{reg} . \mathrm{B}$ \\
\hline D401 & LOOP21 & LXI H C3FB $(\mathrm{H})$ & $21, \mathrm{FB}, \mathrm{C} 3$ & Point memory to LSB of seed \\
\hline D404 & & MOV A,M & $7 \mathrm{E}$ & \\
\hline D405 & & SUB B & 90 & \\
\hline D406 & & MOV M, A & 77 & Subtract reg. B from LSB of seed \\
\hline D407 & & DCX H & $2 \mathrm{~B}$ & Go to next LSB of seed \\
\hline D408 & & MVI $\mathrm{D}, 03(\mathrm{H})$ & 16,03 & Store $0 \times 03$ in $\mathrm{reg}$. D \\
\hline D40A & LOOP19 & MOV A,M & $7 \mathrm{E}$ & \\
\hline D40B & & SBI $00(\mathrm{H})$ & DF, 00 & \\
\hline D40D & & MOV M, A & 77 & $\begin{array}{l}\text { Subtract } 0 \times 00 \text { from current byte of seed with } \\
\text { borrow }\end{array}$ \\
\hline D40E & & DCR D & 15 & Indicates that current seed byte is updated \\
\hline $\mathrm{D} 40 \mathrm{~F}$ & & JZ LOOP18 & $\mathrm{CA}, 16, \mathrm{D} 4$ & If all seed bytes are updated go to LOOP 18 \\
\hline D412 & & DCX H & $2 \mathrm{~B}$ & If not, point memory to next LSB of seed byte \\
\hline D413 & & JMP LOOP19 & $\mathrm{C} 3,0 \mathrm{~A}, \mathrm{D} 4$ & And then go to LOOP19 \\
\hline D416 & LOOP18 & $\mathrm{LXI} \mathrm{H}, \mathrm{C} 3 \mathrm{FB}(\mathrm{H})$ & $21, \mathrm{FB}, \mathrm{C} 3$ & Point memory to MSB of 4 -byte seed \\
\hline D419 & & MOV A,M & $7 \mathrm{E}$ & Load memory contents in accumulator \\
\hline D41A & & INX $\mathrm{H}$ & 23 & Point memory to second MSB of seed \\
\hline D41B & & ORA M & B6 & Are both MSB and second MSB of seed $=0 \times 00 ?$ \\
\hline D41C & & JZ LOOP20 & $\mathrm{CA}, 22, \mathrm{D} 4$ & If yes, go to LOOP 20 \\
\hline $\mathrm{D} 41 \mathrm{~F}$ & & JMP LOOP21 & $\mathrm{C} 3,01, \mathrm{D} 4$ & If not, go to LOOP 21 \\
\hline D422 & LOOP20 & INX H & 23 & Point memory to second LSB of seed \\
\hline D423 & & MOV A,M & $7 \mathrm{E}$ & \\
\hline D424 & & CPI $00(\mathrm{H})$ & $\mathrm{FE}, 00$ & Compare second LSB of seed byte with $0 \times 00$ \\
\hline D426 & & JZ LOOP22 & $\mathrm{CA}, 2 \mathrm{C}, \mathrm{D} 4$ & If they are equal, go to LOOP22 \\
\hline D429 & & JMP LOOP21 & $\mathrm{C} 3,01, \mathrm{D} 4$ & Else, go to LOOP21 \\
\hline D42C & LOOP22 & INX H & 23 & Point memory of LSB of 4 -byte seed \\
\hline D42D & & MOV A,M & $7 \mathrm{E}$ & Load this byte to accumulator \\
\hline D42E & & CMP B & B8 & Compare this byte with contents of reg. B \\
\hline $\mathrm{D} 42 \mathrm{~F}$ & & JZ LOOP23 & $\mathrm{CA}, 38, \mathrm{D} 4$ & If they are equal go to LOOP 23 \\
\hline D432 & & JC LOOP24 & $\mathrm{DA}, 3 \mathrm{~B}, \mathrm{D} 4$ & If byte is less than $0 \times 0 \mathrm{D}$, go to LOOP 24 \\
\hline D435 & & JMP LOOP21 & $\mathrm{C} 3,01, \mathrm{D} 4$ & Else, go to LOOP21 \\
\hline D438 & LOOP23 & MVI A, $00(\mathrm{H})$ & $3 \mathrm{E}, 00$ & \\
\hline D43A & & MOV M, A & 77 & Set LSB of seed to $0 \times 00$ \\
\hline D43B & LOOP24 & LDA $\mathrm{C} 3 \mathrm{FB}(\mathrm{H})$ & $3 \mathrm{~A}, \mathrm{FB}, \mathrm{C} 3$ & \\
\hline D43E & & STA C3F3 $(\mathrm{H})$ & $32, \mathrm{~F} 3, \mathrm{C} 3$ & Store mod 13 random no. in address C3F3 \\
\hline D441 & & MVI A,00(H) & $3 \mathrm{E}, 00$ & \\
\hline D443 & & STA C3F4 $(\mathrm{H})$ & $32, \mathrm{~F} 4, \mathrm{C} 3$ & Set byte 1 of next initial seed to $0 \times 00$ \\
\hline D446 & & MVI A,00(H) & $3 \mathrm{E}, 00$ & \\
\hline D448 & & STA C3F5 $(\mathrm{H})$ & $32, \mathrm{~F} 5, \mathrm{C} 3$ & Set byte 2 of next initial seed to $0 \times 00$ \\
\hline D44B & & MVI A,00(H) & $3 \mathrm{E}, 00$ & \\
\hline D44D & & STA C3F6 $(\mathrm{H})$ & $32, \mathrm{~F} 6, \mathrm{C} 3$ & Set byte 3 of next initial seed to $0 \times 00$ \\
\hline D450 & & MVI A,00(H) & $3 \mathrm{E}, 00$ & \\
\hline D452 & & STA C3F7 (H) & $32, \mathrm{~F} 7, \mathrm{C} 3$ & Set byte 4 of next initial seed to $0 \times 00$ \\
\hline D455 & & LDA $\mathrm{C} 403(\mathrm{H})$ & $3 \mathrm{~A}, 03, \mathrm{C} 4$ & \\
\hline D458 & & STA C3F8 $(\mathrm{H})$ & $32, \mathrm{~F} 8, \mathrm{C} 3$ & $\begin{array}{l}\text { Set byte } 5 \text { of next initial seed to MSB of } \\
\text { the } 4 \text {-byte new seed generated }\end{array}$ \\
\hline D45B & & LDA $\mathrm{C} 404(\mathrm{H})$ & $3 \mathrm{~A}, 04, \mathrm{C} 4$ & \\
\hline D45E & & STA C3F9 $(\mathrm{H})$ & $32, \mathrm{~F} 9, \mathrm{C} 3$ & Set byte 6 of next initial seed to second \\
\hline D461 & & & & MSB of the 4-byte new seed generated \\
\hline D464 & & LDA $\mathrm{C} 405(\mathrm{H})$ & $3 \mathrm{~A}, 05, \mathrm{C} 4$ & \\
\hline D467 & & STA C3FA $(\mathrm{H})$ & $32, \mathrm{FA}, \mathrm{C} 3$ & Set byte 7 of next initial seed to second \\
\hline $\mathrm{D} 46 \mathrm{~A}$ & & & & LSB of the 4-byte new seed generated \\
\hline & & LDA C406(H) & $3 \mathrm{~A}, 06, \mathrm{C} 4$ & \\
\hline D46D & & STA C3FB $(H)$ & $32, \mathrm{FB}, \mathrm{C} 3$ & $\begin{array}{l}\text { Set byte } 8 \text { (LSB) of next initial seed to } \\
\text { LSB of the } 4 \text {-byte new seed generated }\end{array}$ \\
\hline & & RET & $\mathrm{C} 9$ & \\
\hline
\end{tabular}




\section{Conclusion}

Hence, as discussed in section $6,1 \mathrm{kB}$ of data have been encrypted byte-wise with random pair of prime numbers being used as initial conditions for the same. After running this program, the message bytes which are stored in addresses FBE8 - FFCF are encrypted and the respective ciphertext bytes are stored in address locations F000 - F7CF. F000 and F001 contain the MSB and LSB of the first ciphertext respectively, F002 and F003 contain those of the second ciphertext and so on. In a similar fashion, the decryption of the received bytes can be performed cyclically at the receiver's end utilizing codes in section 3.2 and 5. Now, the private key will contain all the pairs of prime numbers $p$ and $q$ used for encryption and also the respective private key exponent $(d)$ values i.e.

$P^{\prime}=\left\{p_{1}, p_{2}, \cdots, q_{1}, q_{2}, \cdots, d_{1}, d_{2}, \cdots\right\}$ where the pair $\left\{p_{i}, q_{i}\right\}$ is the pair of primes used to encrypt $i^{\text {th }}$ byte of message data and $d_{i}$ is the corresponding private key exponent. Similarly, the public key will contain the common public key exponent and the products of every set of prime numbers used in encryption i.e $P=\left\{e, n_{1}, n_{2}, \cdots\right\}$ where $n_{i}=p_{i} q_{i}$.

\section{References}

[1] Evgeny Milanov. The RSA Algorithm. (2009) Available: https://sites.math.washington.edu/ morrow/336_09/papers/Yevgeny.pdf

[2] Cesar Alison Monteiro Paixão. An efficient variant of the RSA cryptosystem. (2003) (preprint). Available: https://eprint.iacr.org/2003/159.pdf

[3] Seema Verma, Deepak Garg. An Improved RSA Variant. International Journal of Advancements in Technology. ISSN 0976-4860

[4] Mihir Bellare, Shafi Goldwassery and Daniele Micciancioz. "Pseudo-Random"Number Generation within Cryptographic Algorithms: the DSS Case. Appears in Advances in Cryptology - Crypto 97 Proceedings, Lecture Notes in Computer Science Vol. 1294, B. Kaliski ed., Springer-Verlag, 1997. 